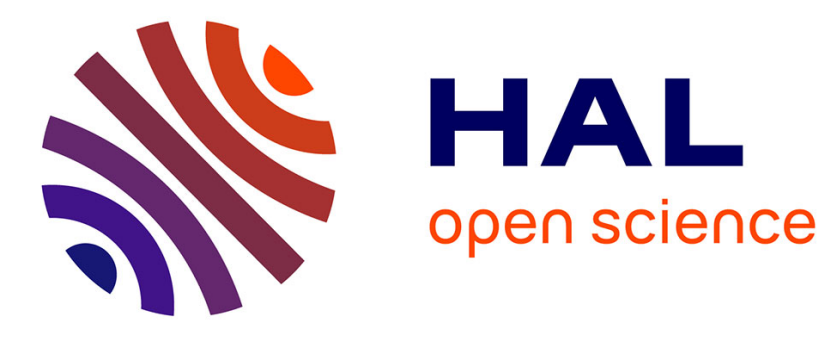

\title{
Cyclopentadienylmolybdenum(II) and -(III) Complexes Containing Diene and Allyl Ligands. 1. Isomeric Preferences and Isomerization Rates in a Pair of Redox-Related Organometallic Complexes
}

\author{
Li-Sheng Wang, James C Fettinger, Rinaldo Poli
}

\section{To cite this version:}

Li-Sheng Wang, James C Fettinger, Rinaldo Poli. Cyclopentadienylmolybdenum(II) and -(III) Complexes Containing Diene and Allyl Ligands. 1. Isomeric Preferences and Isomerization Rates in a Pair of Redox-Related Organometallic Complexes. Journal of the American Chemical Society, 1997, 119 (19), pp.4453-4464. 10.1021/ja964078k . hal-03309755

\section{HAL Id: hal-03309755 \\ https://hal.science/hal-03309755}

Submitted on 30 Jul 2021

HAL is a multi-disciplinary open access archive for the deposit and dissemination of scientific research documents, whether they are published or not. The documents may come from teaching and research institutions in France or abroad, or from public or private research centers.
L'archive ouverte pluridisciplinaire HAL, est destinée au dépôt et à la diffusion de documents scientifiques de niveau recherche, publiés ou non, émanant des établissements d'enseignement et de recherche français ou étrangers, des laboratoires publics ou privés. 
Submitted to J. Am. Chem. Soc. 11/96

Revised version submitted 2/97

\section{Cyclopentadienylmolybdenum(II) and -(III) Complexes Containing Diene and Allyl}

Ligands. 1. Isomeric Preferences and Isomerization Rates in a Pair of Redox-Related Organometallic Complexes

Li-Sheng Wang, ${ }^{1 a}$ James C. Fettinger ${ }^{1 \mathrm{a}}$ and Rinaldo Poli*1a,b

Department of Chemistry and Biochemistry, University of Maryland, College Park, Maryland 20742 and Laboratoire de Synthèse et d'Electrosynthèse Organométallique, Faculté des Sciences "Gabriel", Université de Bourgogne, 6 Boulevard Gabriel, 21100 Dijon (France)

Correspondence to: Prof. Rinaldo Poli

Laboratoire de Synthèse et d'Electrosynthèse Organométallique

Faculté des Sciences "Gabriel"

6, Boulevard Gabriel

21100 Dijon (France)

tel: $+33-03.80 .39 .68 .81$

fax: $+33-03.80 .39 .60 .98$

E-MAIL: Rinaldo.Poli@u-bourgogne.fr 


\begin{abstract}
Treatment of $\mathrm{CpMoCl}_{2}\left(\eta-\mathrm{C}_{4} \mathrm{H}_{6}\right)$ (1) with 1 equiv of allylmagnesium bromide yields the dinuclear complexes $\left[\mathrm{CpMo}\left(\eta-\mathrm{C}_{4} \mathrm{H}_{6}\right)(\mu-\mathrm{Br})\right]_{2}(\mathbf{2}$, major $)$ and $\mathrm{Cp}_{2} \mathrm{Mo}_{2}\left(\eta-\mathrm{C}_{4} \mathrm{H}_{6}\right)_{2}(\mu-\mathrm{Br})(\mu-$ Cl) (3, minor). A solid solution of compounds $\mathbf{2}$ and $\mathbf{3}$ adopts an anti geometry in the solid state, as shown by X-ray crystallography, whereas both anti and syn isomers are observed in benzene solution by ${ }^{1} \mathrm{H}$ NMR spectroscopy. The reaction of 1 with 2 equiv of allylmagnesium bromide yields $\left[\mathrm{CpMo}\left(\eta-\mathrm{C}_{3} \mathrm{H}_{5}\right)\left(\eta-\mathrm{C}_{4} \mathrm{H}_{6}\right)\right]$ as an equilibrium mixture of a major $(98 \%, 4 \mathbf{a})$ and a minor $(2 \%, 4 \mathbf{b})$ isomer. NOE-NMR studies indicate the $\mathrm{CpMo}\left(\right.$ prone- $\left.\mathrm{C}_{3} \mathrm{H}_{5}\right)\left(\right.$ supine- $\left.\mathrm{C}_{4} \mathrm{H}_{6}\right)$ orientation for the major isomer $\mathbf{4 a}$, which is also found in the solid state by X-ray crystallography. The orientation of $\mathbf{4 b}$ is suggested by the ${ }^{1} \mathrm{H}-\mathrm{NMR}$ chemical shifts as $\mathrm{CpMo}\left(\right.$ supine $\left.-\mathrm{C}_{3} \mathrm{H}_{5}\right)\left(\right.$ supine $\left.-\mathrm{C}_{4} \mathrm{H}_{6}\right)$. Oxidation of $\mathbf{4 a} / \mathbf{b}$ by ferrocenium hexafluorophosphate in dichloromethane gives the 17-electron compounds $\left[\mathrm{CpMo}\left(\eta-\mathrm{C}_{3} \mathrm{H}_{5}\right)\left(\eta-\mathrm{C}_{4} \mathrm{H}_{6}\right)\right]\left[\mathrm{PF}_{6}\right](\mathbf{5 a} / \mathbf{b})$. The green compound $\mathbf{5 a}$ converts into the more stable red-violet $\mathbf{5 b}$ with an estimated half-life of $<20 \mathrm{~s}$ in THF. It can be observed, however, at low temperature by EPR spectroscopy. The $\left[\mathrm{CpMo}\left(\right.\right.$ supine- $\left.\eta-\mathrm{C}_{3} \mathrm{H}_{5}\right)\left(\right.$ supine $\left.\left.-\eta-\mathrm{C}_{4} \mathrm{H}_{6}\right)\right]\left[\mathrm{PF}_{6}\right]$ configuration for $\mathbf{5 b}$ has been confirmed by $\mathrm{X}-$ ray diffraction methods. Upon reduction with cobaltocene, $\mathbf{5 b}$ is converted selectively to $\mathbf{4 b}$, followed by slow equilibration $\left(\mathrm{t}_{1 / 2}=6.5 \mathrm{~h}\right)$ with $4 \mathbf{a}$. Refluxing or photolyzing a solution of 4a/b in benzene generates a third isomer, $4 \mathbf{c}$, which adopts a $\mathrm{CpMo}\left(\right.$ supine- $\left.\mathrm{C}_{3} \mathrm{H}_{5}\right)($ s-trans$\mathrm{C}_{4} \mathrm{H}_{6}$ ) configuration as confirmed by an X-ray analysis. The distribution of $\mathbf{4 a}$ and $\mathbf{4 c}$ at equilibrium is approximately 1:1 either by starting from $\mathbf{4 a / b}$ or from pure $\mathbf{4 c}$ and independent of equilibration method (thermal/photochemical). Oxidation of $\mathbf{4 c}$ generates the corresponding 1-electron oxidation product $\mathbf{5 c}$, which rapidly isomerizes to $\mathbf{5 b}$. It can be observed, however, by EPR in THF together with a fourth isomer 5d (ca. 1:1), believed to differ from $\mathbf{5 c}$ only in the orientation of the allyl ligand. Equilibrium, rate, and electrochemical data allow to sort out most of the thermodynamic and kinetic parameters related to the transformation of the different compounds. The faster s-trans- to s-cis-butadiene isomerization for 5 relative to 4 indicates the easier accessibility of the unsaturated 15-electron vs. 16-electron intermediate. Possible reasons for this trend are analyzed.
\end{abstract}




\section{Introduction}

Transition metal complexes containing allyl ligands and/or conjugated diene ligands have attracted considerable attention, due to the importance of these complexes as starting materials or reactive intermediates in catalytic processes, ${ }^{2}$ and as reaction substrates in organic synthesis. $^{3}$ On the other hand, the coordination chemistry of allyl and diene ligands is of interest in terms of the variable coordination modes and different reactivities. ${ }^{4,5}$ In addition, compounds that contain contemporarily a butadiene and an allyl ligand are important models for diene polymerization catalysts or are themselves catalytically active. ${ }^{6-11}$ As a continuation of our studies of cyclopentadienylmolybdenum(II) complexes having unsaturated hydrocarbons as ligands, ${ }^{12}$ our attention has focused on the direct synthesis of previously unreported diene-allyl complexes. In this first paper of a series, we present our results on the preparation and characterization of the diamagnetic complex $\mathrm{CpMo}\left(\eta-\mathrm{C}_{3} \mathrm{H}_{5}\right)\left(\eta-\mathrm{C}_{4} \mathrm{H}_{6}\right)$ in three different isomeric forms, and its paramagnetic one-electron oxidation product, $[\mathrm{CpMo}(\eta-$ $\left.\left.\mathrm{C}_{3} \mathrm{H}_{5}\right)\left(\eta-\mathrm{C}_{4} \mathrm{H}_{6}\right)\right]^{+}$, in four different isomeric forms. The isolation and characterization of a halide-bridged dinuclear Mo(II) intermediate is also reported. Later contributions will deal with the chemical reactivity of these compounds and with their activity as butadiene polymerization catalysts.

\section{Experimental}

General Procedures. All reactions were conducted by standard Schlenk-line techniques under a dinitrogen atmosphere. Solvents were dried by conventional methods (THF and $\mathrm{Et}_{2} \mathrm{O}$ on $\mathrm{Na} / \mathrm{K} /$ benzophenone, toluene and heptane on $\mathrm{Na}, \mathrm{CH}_{2} \mathrm{Cl}_{2}$ and $\mathrm{CHCl}_{2} \mathrm{CH}_{2} \mathrm{Cl}$ from $\left.\mathrm{P}_{4} \mathrm{O}_{10}\right)$ and distilled directly from the drying agent under dinitrogen or argon. All routine NMR experiments were carried out on a Bruker AM400 spectrometer, while 2D-NMR and ${ }^{13} \mathrm{C}-\mathrm{NMR}$ data were obtained from a Bruker AMX500 spectrometer. EPR spectra were recorded on a Bruker ER200 spectrometer upgraded to ESP300 and IR spectra on a Perkin-Elmer FTIR 1600 
spectrophotometer. Cyclic voltammograms were recorded with an EG\&G 362 potentiostat connected to a Macintosh computer through MacLab hardware/software; the electrochemical cell was a locally modified Schlenk tube with a Pt counterelectrode sealed through uranium glass/Pyrex glass seals. The cell was fitted with a $\mathrm{Ag} / \mathrm{AgCl}$ reference electrode and a $\mathrm{Pt}$ working electrode. All potentials are reported vs. the $\mathrm{Cp}_{2} \mathrm{Fe} / \mathrm{Cp}_{2} \mathrm{Fe}^{+}$couple which was introduced into the cell at the end of each measurement. Elemental analyses were performed by $\mathrm{M}-\mathrm{H}-\mathrm{W}$ Laboratories, Phoenix, AZ. Compound $\mathrm{CpMoCl}_{2}$ was prepared as previously described. ${ }^{13}$ The $\mathrm{C}_{3} \mathrm{H}_{5} \mathrm{MgBr}$ solution in $\mathrm{Et}_{2} \mathrm{O}\left(1 \mathrm{M}\right.$, Aldrich) was used as received. All ${ }^{1} \mathrm{H}$ and ${ }^{13} \mathrm{C}-\mathrm{NMR}$ data are given in Table 1.

Preparation of $\mathbf{C p M o C l}_{2}\left(\eta-\mathbf{C}_{4} \mathbf{H}_{6}\right)$ (1). $\mathrm{CpMoCl}_{2}(4.50 \mathrm{~g}, 19.4 \mathrm{mmol})$ was suspended in $100 \mathrm{~mL}$ of THF. Excess butadiene was condensed into the mixture (the volume of the liquid increased by ca. $20 \mathrm{~mL}$ ), followed by heating to $70-80^{\circ} \mathrm{C}$ for $4 \mathrm{~h}$ with magnetic stirring. The yellow brown solid gradually dissolved to yield a red brown suspension. After cooling to room temperature, the solvent was reduced to ca. $10 \mathrm{~mL}$ by evaporation under reduced pressure and $n$-heptane $(100 \mathrm{~mL})$ was added to complete the precipitation of the product. The supernatant was decanted off and the crystalline red-brown solid was washed with several portions of $n$ heptane (total ca. $100 \mathrm{~mL}$ ) and dried under vacuum overnight (yield $5.13 \mathrm{~g}, 90 \%$ ). EPR (THF): $\mathrm{g}=2.012, \mathrm{a}_{\mathrm{Mo}}=38 \mathrm{G}$. The physical and spectroscopic properties of this material match those previously reported. ${ }^{14}$ 
Table 1. ${ }^{1} \mathrm{H}$ - and ${ }^{13} \mathrm{C}-\mathrm{NMR}$ Data ${ }^{a}$

\begin{tabular}{|c|c|c|}
\hline compd & ${ }^{1} \mathrm{H}-\mathrm{NMR}(\delta)$ & ${ }^{13} \mathrm{C}-\mathrm{NMR}(\delta)$ \\
\hline anti-[CpMo $\left.\left(\eta-\mathrm{C}_{4} \mathrm{H}_{6}\right)(\mu-\mathrm{Br})\right]_{2}(\mathbf{2 a})^{b}$ & $7.54\left(\mathrm{~m}, 4 \mathrm{H}, \mathrm{H}_{\mathrm{a}}\right) ; 4.53(\mathrm{~s}, 10 \mathrm{H}, \mathrm{Cp}) ; 2.30\left(\mathrm{~m}, 4 \mathrm{H}, \mathrm{H}_{\mathrm{b}}\right) ; 0.06\left(\mathrm{~m}, 4 \mathrm{H}, \mathrm{H}_{\mathrm{c}}\right)$ & $\begin{array}{l}122.7\left(\mathrm{~d},{ }^{1} J_{\mathrm{CH}}=164 \mathrm{~Hz}, \mathrm{C}_{\mathrm{a}}\right) ; 94.3\left(\mathrm{dm},{ }^{1} J_{\mathrm{CH}}\right. \\
=178 \mathrm{~Hz}, \mathrm{Cp}) ; 46.3\left(\mathrm{t},{ }^{1} J_{\mathrm{CH}}=155 \mathrm{~Hz}, \mathrm{C}_{\mathrm{bc}}\right)\end{array}$ \\
\hline $\operatorname{syn}-\left[\mathrm{CpMo}\left(\eta-\mathrm{C}_{4} \mathrm{H}_{6}\right)(\mu-\mathrm{Br})\right]_{2}(\mathbf{2 b})^{b}$ & $7.13\left(\mathrm{~m}, 4 \mathrm{H}, \mathrm{H}_{\mathrm{a}}\right) ; 4.35(\mathrm{~s}, 10 \mathrm{H}, \mathrm{Cp}) ; 2.20\left(\mathrm{~m}, 4 \mathrm{H}, \mathrm{H}_{\mathrm{b}}\right) ;-0.02\left(\mathrm{~m}, 4 \mathrm{H}, \mathrm{H}_{\mathrm{c}}\right)$ & $\begin{array}{l}122.5\left(\mathrm{~d},{ }^{1} J_{\mathrm{CH}}=164 \mathrm{~Hz}, \mathrm{C}_{\mathrm{a}}\right) ; 94.5\left(\mathrm{dm},{ }^{1} J_{\mathrm{CH}}\right. \\
=178 \mathrm{~Hz}, \mathrm{Cp}) ; 46.2\left(\mathrm{t},{ }^{1} J_{\mathrm{CH}}=155 \mathrm{~Hz}, \mathrm{C}_{\mathrm{bc}}\right)\end{array}$ \\
\hline anti-Cp $\mathrm{Cp}_{2} \mathrm{Mo}_{2}\left(\eta-\mathrm{C}_{4} \mathrm{H}_{6}\right)_{2}(\mu-\mathrm{Br})(\mu-\mathrm{Cl})(\mathbf{3 a})^{b}$ & $\begin{array}{l}7.67\left(\mathrm{ddddd}, 2 \mathrm{H}, \mathrm{H}_{\mathrm{a}},{ }^{3} J_{\mathrm{HHc}}=8.9 \mathrm{~Hz},{ }^{3} J_{\mathrm{HHb}}={ }^{3} J_{\mathrm{HHa}}=6.9 \mathrm{~Hz},{ }^{4} J_{\mathrm{HHb}}={ }^{4} J_{\mathrm{HHc}^{\prime}}=\right. \\
1.2 \mathrm{~Hz}) ; 7.37\left(\mathrm{ddddd}, 2 \mathrm{H}, \mathrm{H}_{\mathrm{a}^{\prime}},{ }^{3} J_{\mathrm{HHc}}=8.4 \mathrm{~Hz},{ }^{3} J_{\mathrm{HHb}^{\prime}}={ }^{3} J_{\mathrm{HHa}}=7.9 \mathrm{~Hz},{ }^{4} \mathrm{~J}_{\mathrm{HHb}}=\right. \\
\left.{ }^{4} J_{\mathrm{HHc}}=1.2 \mathrm{~Hz}\right) ; 4.53(\mathrm{~s}, 10 \mathrm{H}, \mathrm{Cp}) ; 2.37\left(\mathrm{ddd}, 2 \mathrm{H}, \mathrm{H}_{\mathrm{b}},{ }^{3} J_{\mathrm{HHa}}=6.9 \mathrm{~Hz},{ }^{2} J_{\mathrm{HHc}}=\right. \\
\left.{ }^{4} J_{\mathrm{HHa}}=1.5 \mathrm{~Hz}\right) ; 2.35\left(\mathrm{ddd}, 2 \mathrm{H}, \mathrm{H}_{\mathrm{b}^{\prime}},{ }^{3} J_{\mathrm{HHa}}=6.9 \mathrm{~Hz},{ }^{2} J_{\mathrm{HHc}}={ }^{4} J_{\mathrm{HHa}}=1.2 \mathrm{~Hz}\right) ; \\
\left.\left.0.08 \text { (overlap, } \mathrm{H}_{\mathrm{c}}\right) ; 0.00 \text { (overlap, } \mathrm{H}_{\mathrm{c}^{\prime}}\right)\end{array}$ & \\
\hline $\operatorname{syn}-\mathrm{Cp}_{2} \mathrm{Mo}_{2}\left(\eta-\mathrm{C}_{4} \mathrm{H}_{6}\right)_{2}(\mu-\mathrm{Br})(\mu-\mathrm{Cl})(\mathbf{3 b})^{b}$ & $\begin{array}{l}7.24\left(\mathrm{ddddd}, 2 \mathrm{H}, \mathrm{H}_{\mathrm{a}},{ }^{3} J_{\mathrm{HHc}}=8.9 \mathrm{~Hz},{ }^{3} J_{\mathrm{HHb}}={ }^{3} J_{\mathrm{HHa}}=7.4 \mathrm{~Hz},{ }^{4} J_{\mathrm{HHb}}={ }^{4} J_{\mathrm{HHc}}=\right. \\
1.2 \mathrm{~Hz}) ; 6.87\left(\mathrm{ddddd}, 2 \mathrm{H}, \mathrm{H}_{\mathrm{a}^{\prime}},{ }^{3} J_{\mathrm{HH}}=8.9 \mathrm{~Hz},{ }^{3} J_{\mathrm{HHb}}={ }^{3} J_{\mathrm{HHa}}=7.4 \mathrm{~Hz},{ }^{4} J_{\mathrm{HHb}}=\right. \\
\left.{ }^{4} J_{\mathrm{HHc}}=1.5 \mathrm{~Hz}\right) ; 4.33(\mathrm{~s}, 10 \mathrm{H}, \mathrm{Cp}) ; 2.24\left(\mathrm{ddd}, 2 \mathrm{H}, \mathrm{H}_{\mathrm{b}},{ }^{3} J_{\mathrm{HHa}}=7.9 \mathrm{~Hz},{ }^{2} J_{\mathrm{HHc}}=\right. \\
\left.{ }^{4} J_{\mathrm{HHa}}=1.5 \mathrm{~Hz}\right) ; 2.24\left(\mathrm{ddd}, 2 \mathrm{H}, \mathrm{H}_{\mathrm{b}^{\prime}},{ }^{3} J_{\mathrm{HHa}}=7.9 \mathrm{~Hz},{ }^{2} J_{\mathrm{HHc}}={ }^{4} J_{\mathrm{HHa}}=1.5 \mathrm{~Hz}\right) ; \\
0.04\left(\text { overlap, } \mathrm{H}_{\mathrm{c}}\right) ;-0.08\left(\mathrm{dddd}, 2 \mathrm{H}, \mathrm{H}_{\mathrm{c}^{\prime}},{ }^{3} J_{\mathrm{HHa}}=8.9 \mathrm{~Hz},{ }^{2} J_{\mathrm{HHb}}=1.6 \mathrm{~Hz},{ }^{4} J_{\mathrm{HHa}}\right. \\
\left.=1.4 \mathrm{~Hz},{ }^{5} J_{\mathrm{HHc}}=1.4 \mathrm{~Hz}\right)\end{array}$ & \\
\hline$\left[\mathrm{CpMo}\left(\right.\right.$ prone- $\left.\eta-\mathrm{C}_{3} \mathrm{H}_{5}\right)\left(\right.$ supine- $\left.\left.\eta-\mathrm{C}_{4} \mathrm{H}_{6}\right)\right](\mathbf{4 a})^{c}$ & $\begin{array}{l}4.26(\mathrm{~s}, 5 \mathrm{H}, \mathrm{Cp}) ; 4.18\left(\mathrm{~m}, 2 \mathrm{H}, \mathrm{H}_{\mathrm{a}}\right) ; 2.89\left(\mathrm{~m}, 2 \mathrm{H}, \mathrm{H}_{\mathrm{b}}\right) ; 2.35\left(\mathrm{tt}, 1 \mathrm{H}, \mathrm{H}_{\mathrm{d}},{ }^{3} J_{\mathrm{HHf}}=\right. \\
\left.11 \mathrm{~Hz},{ }^{3} J_{\mathrm{HHe}}=8.9 \mathrm{~Hz}\right) ; 1.70\left(\mathrm{dm}, 2 \mathrm{H}, \mathrm{H}_{\mathrm{e}},{ }^{3} J_{\mathrm{HHd}}=9 \mathrm{~Hz}\right) ; 0.72\left(\mathrm{dm}, 2 \mathrm{H}, \mathrm{H}_{\mathrm{f}},{ }^{3} J_{\mathrm{HHd}}\right. \\
=11 \mathrm{~Hz}) ; 0.58\left(\mathrm{~m}, 2 \mathrm{H}, \mathrm{H}_{\mathrm{c}}\right)\end{array}$ & $\begin{array}{l}108.6\left(\mathrm{dm}, \mathrm{C}_{\mathrm{a}},{ }^{1} J_{\mathrm{CH}}=162 \mathrm{~Hz}\right) ; 89.3(\mathrm{dm}, \\
\left.\mathrm{Cp},{ }^{1} J_{\mathrm{CH}}=177 \mathrm{~Hz}\right) ; 69.6\left(\mathrm{~d}, \mathrm{C}_{\mathrm{d}},{ }^{1} J_{\mathrm{CH}}=157\right. \\
\mathrm{Hz}) ; 39.4\left(\mathrm{td}, \mathrm{C}_{\mathrm{bc}},{ }^{1} J_{\mathrm{CH}}=154 \mathrm{~Hz},{ }^{2} J_{\mathrm{CH}}=7\right. \\
\mathrm{Hz}) ; 31.8\left(\mathrm{td}, \mathrm{C}_{\mathrm{e}},{ }^{1} J_{\mathrm{CH}}=153 \mathrm{~Hz},{ }^{2} J_{\mathrm{CH}}=7\right. \\
\mathrm{Hz})\end{array}$ \\
\hline$\left[\mathrm{CpMo}\left(\right.\right.$ supine $\left.-\eta-\mathrm{C}_{3} \mathrm{H}_{5}\right)\left(\right.$ supine $\left.\left.-\eta-\mathrm{C}_{4} \mathrm{H}_{6}\right)\right](\mathbf{4 b})^{c}$ & $\begin{array}{l}4.10(\mathrm{~s}, 5 \mathrm{H}, \mathrm{Cp}) ; 3.95\left(\mathrm{~m}, 2 \mathrm{H}, \mathrm{H}_{\mathrm{a}}\right) ; 3.77\left(\mathrm{tt}, 1 \mathrm{H}, \mathrm{H}_{\mathrm{d}},{ }^{3} J_{\mathrm{HHf}}=14 \mathrm{~Hz},{ }^{3} J_{\mathrm{HHe}}=8.5\right. \\
\mathrm{Hz}) ; 2.73\left(\mathrm{~m}, 2 \mathrm{H}_{\mathrm{e}},{ }^{3} J_{\mathrm{HHd}}=8.5 \mathrm{~Hz}\right) ; 2.41\left(\mathrm{~m}, 2 \mathrm{H}, \mathrm{H}_{\mathrm{b}}\right) ; 1.22\left(\mathrm{dm}, 2 \mathrm{H}, \mathrm{H}_{\mathrm{f}},{ }^{3} J_{\mathrm{HHd}}=\right. \\
14 \mathrm{~Hz}) ; 0.33\left(\mathrm{~m}, 2 \mathrm{H}_{\mathrm{c}}\right)\end{array}$ & \\
\hline$\left[\mathrm{CpMo}\left(\right.\right.$ supine- $\left.\eta-\mathrm{C}_{3} \mathrm{H}_{5}\right)\left(\right.$ s-trans $\left.\left.-\mathrm{C}_{4} \mathrm{H}_{6}\right)\right](\mathbf{4 c})^{d}$ & $\begin{array}{l}4.41(\mathrm{~s}, 5 \mathrm{H}, \mathrm{Cp}) ; 2.56\left(\mathrm{dd}, 1 \mathrm{H}, \mathrm{H}_{\mathrm{e}},{ }^{3} J_{\mathrm{HHd}}=5.7 \mathrm{~Hz},{ }^{4} J_{\mathrm{HH}}{ }^{\prime}=3.3 \mathrm{~Hz}\right) ; 2.48(\mathrm{~d}, 1 \mathrm{H}, \\
\left.\mathrm{H}_{\mathrm{b}},{ }^{3} J_{\mathrm{HHa}}=10.7 \mathrm{~Hz}\right) ; \sim 2.3\left(\mathrm{~m}, 1 \mathrm{H}, \mathrm{H}_{\mathrm{d}}\right) ; \sim 2.3\left(\mathrm{~m}, 1 \mathrm{H}, \mathrm{H}_{\mathrm{a}^{\prime}}\right) ; 2.21\left(\mathrm{~d}, 1 \mathrm{H}, \mathrm{H}_{\mathrm{f}},{ }^{3} J_{\mathrm{HHd}}\right. \\
=10.0 \mathrm{~Hz}) ; \\
2.06\left(\mathrm{~d}, 2 \mathrm{H}, \mathrm{H}_{\mathrm{c}} \text { and } \mathrm{H}_{\mathrm{c}^{\prime}},{ }^{3} J_{\mathrm{HcHa}}={ }^{3} J_{\mathrm{H}^{\prime} \mathrm{Ha}^{\prime}}=5.6 \mathrm{~Hz}\right) ; 1.77\left(\mathrm{ddd}, 1 \mathrm{H}, \mathrm{H}_{\mathrm{a}},{ }^{3} J_{\mathrm{HHb}}=\right. \\
\left.10.7 \mathrm{~Hz} ;{ }^{3} J_{\mathrm{HHc}}=5.6 \mathrm{~Hz},{ }^{3} J_{\mathrm{HHa}}=5.0 \mathrm{~Hz}\right) ; 1.37\left(\mathrm{~d}, 1 \mathrm{H}, \mathrm{H}_{\mathrm{f}},{ }^{3} J_{\mathrm{HHd}}=9.6 \mathrm{~Hz}\right) ; 0.97 \\
\left(\mathrm{dd}, 1 \mathrm{H}, \mathrm{H}_{\mathrm{e}},{ }^{3}{ }^{3} \mathrm{HHd}_{\mathrm{HHd}}=6.0 \mathrm{~Hz},{ }^{3} J_{\mathrm{HHe}}=3.3 \mathrm{~Hz}\right) ; 0.43\left(\mathrm{dd}, 1 \mathrm{H}, \mathrm{H}_{\mathrm{b}},{ }^{3} J_{\mathrm{HHa}^{\prime}}=9.6 \mathrm{~Hz},\right. \\
\left.J_{\mathrm{HHc}^{\prime}}=1.7 \mathrm{~Hz}\right)\end{array}$ & $\begin{array}{l}91.5(\mathrm{Cp}) ; 87.5\left(\mathrm{C}_{\mathrm{a}^{\prime}}\right) ; 84.5\left(\mathrm{C}_{\mathrm{a}}\right) ; 69.1\left(\mathrm{C}_{\mathrm{d}}\right) ; \\
52.3\left(\mathrm{C}_{\mathrm{bc}}\right) ; 46.9\left(\mathrm{C}_{\mathrm{eff}}\right) ; 45.2\left(\mathrm{C}_{\mathrm{b}^{\prime} \mathrm{c}^{\prime}}\right) ; 42.0\left(\mathrm{C}_{\mathrm{e}^{\prime} \mathrm{f}}\right)\end{array}$ \\
\hline
\end{tabular}

${ }^{a}$ All spectra were recorded in $\mathrm{C}_{6} \mathrm{D}_{6} \cdot{ }^{b}$ For atom nomenclature, refer to I. ${ }^{c}$ For atom nomenclature, refer to III. ${ }^{d}$ For atom nomenclature, refer to IV. 


\section{Preparation of $\left[\mathrm{CpMo}\left(\eta-\mathrm{C}_{4} \mathrm{H}_{6}\right)(\mu-\mathrm{Br})\right]_{2}$ (2) and $\mathrm{Cp}_{2} \mathrm{Mo}_{2}\left(\eta-\mathrm{C}_{4} \mathrm{H}_{6}\right)_{2}(\mu-\mathrm{Br})(\mu-\mathrm{Cl})$}

(3). $\mathrm{CpMoCl}_{2}\left(\eta-\mathrm{C}_{4} \mathrm{H}_{6}\right)(0.850 \mathrm{~g}, 2.97 \mathrm{mmol})$ was suspended in $30 \mathrm{~mL}$ of THF, the resulting mixture was cooled to $-78^{\circ} \mathrm{C}$, and $3.3 \mathrm{~mL}$ of a $\mathrm{Et}_{2} \mathrm{O}$ solution of $\mathrm{C}_{3} \mathrm{H}_{5} \mathrm{MgBr}(1 \mathrm{M}, 3.3 \mathrm{mmol})$ was added. The red-brown suspension turned green within $1 \mathrm{~h}$. The mixture was stirred for an additional hour, yielding a yellow-green precipitate. The supernatant liquid was decanted off at $-78^{\circ} \mathrm{C}$ and the solid was dissolved in $300 \mathrm{~mL}$ of toluene at room temperature, followed by filtration through Celite. The solution was evaporated under reduced pressure to dryness, yielding the product as a yellow-green solid in $92 \%$ yield $(0.806 \mathrm{~g})$. Since the product is a mixture, an elemental analysis was not attempted. Low-resolution anionic mass spectrum (FAB-): $m / z \quad 81\left[^{81} \mathrm{Br}\right]^{-} 98 \% ; 79$ [ $\left.{ }^{79} \mathrm{Br}\right]^{-} 100 \%$. A ${ }^{1} \mathrm{H}-\mathrm{NMR}$ spectrum indicates the presence of $86 \%$ of 2 and $14 \%$ of $\mathbf{3}$, following the peak assignments shown in Table 1 (see Results). A single crystal for the X-ray analysis was obtained by recrystallization from slow diffusion of a $n$-heptane layer into a THF solution.

Reaction of $\left[\mathrm{CpMo}\left(\mathrm{C}_{4} \mathrm{H}_{6}\right)(\mu-\mathrm{Br})\right]_{2} \quad$ (2) and $\mathrm{Cp}_{2} \mathrm{Mo}_{2}\left(\mathrm{C}_{4} \mathrm{H}_{6}\right)_{2}(\mu-\mathrm{Br})(\mu-$ $\mathrm{Cl}) \mathrm{CpMo}\left(\mathrm{C}_{4} \mathrm{H}_{6}\right)$ (3) with $\mathrm{PPN}^{+} \mathrm{Cl}^{-}$. A sample of crystals the $2 / 3$ mixture (ca. $2 \mathrm{mg}$ ) and $\mathrm{PPN}^{+} \mathrm{Cl}^{-}$(ca. $2 \mathrm{mg}$ ) were placed in an $\mathrm{NMR}$ tube and ca. $0.5 \mathrm{~mL}$ of $\mathrm{C}_{6} \mathrm{D}_{6}$ was added. The suspension was heated at the reflux temperature for $1 \mathrm{~min}$. The ${ }^{1} \mathrm{H}-\mathrm{NMR}$ spectrum of the resulting mixture indicated a $\mathbf{2} / \mathbf{3}$ ratio of $61: 39$.

Preparation of $\mathrm{CpMo}\left(\eta-\mathrm{C}_{3} \mathrm{H}_{5}\right)\left(\eta-\mathrm{C}_{4} \mathrm{H}_{6}\right)$ (4a and $\left.4 \mathrm{~b}\right)$. To a suspension of $\mathrm{CpMoCl}_{2}\left(\eta-\mathrm{C}_{4} \mathrm{H}_{6}\right)(1.000 \mathrm{~g}, 3.50 \mathrm{mmol})$ in $30 \mathrm{~mL}$ of THF was added $7.7 \mathrm{~mL}$ of a $\mathrm{Et}_{2} \mathrm{O}$ solution of $\mathrm{C}_{3} \mathrm{H}_{5} \mathrm{MgBr}(1 \mathrm{M}, 7.7 \mathrm{mmol})$ at $-78^{\circ} \mathrm{C}$. The red-brown suspension gradually turned green within $0.5 \mathrm{~h}$. After further stirring for $2 \mathrm{~h}$ at $-78^{\circ} \mathrm{C}$, the temperature was gradually elevated to $-20^{\circ} \mathrm{C}$, at which point the green suspension quickly turned red-brown. The solvent was removed under reduced pressure at $-20^{\circ} \mathrm{C}$, followed by extraction of the residue with $n$-heptane at room temperature (ca. $50 \mathrm{~mL}$ ). The supernatant liquid was decanted into another Schlenk and concentrated to ca. $1 / 2$ of its original volume, followed by cooling to $-80^{\circ} \mathrm{C}$ overnight, to yield the product as a red-brown crystalline solid. The supernatant liquid was decanted off and the solid was dried under vacuum (yield $666 \mathrm{mg}$, 74\%). Anal. Calcd. for $\mathrm{C}_{12} \mathrm{H}_{16} \mathrm{Mo}$ : C, 56.25; 
H, 6.25. Found: C, 56.0; H, 6.4. The ratio of $\mathbf{4 a}$ and $\mathbf{4 b}$ as determined by ${ }^{1} \mathrm{H}$ NMR was $98: 2$. This product does not decompose in the solid state upon brief exposure to air, but it is significantly deteriorated upon exposure for several hours. Crystals suitable for the X-ray crystallographic analysis were obtained from recrystallization from diethyl ether at $-80^{\circ} \mathrm{C}$.

Preparation of CpMo(supine- $\left.\eta-\mathrm{C}_{3} \mathrm{H}_{5}\right)\left(s-t r a n s-\eta-\mathrm{C}_{4} \mathrm{H}_{6}\right)$ (4c). (a) By UV irradiation. A $\mathrm{C}_{6} \mathrm{D}_{6}$ solution of the equilibrium mixture of $\mathbf{4 a} / \mathbf{b}(800 \mathrm{mg}, 3.13 \mathrm{mmol}$ in $30 \mathrm{~mL})$ was irradiated overnight by a UV Xe lamp, resulting in a darkening of the deep red-brown solution. The Schlenk was immersed in a water bath, which served to maintain the temperature below $40{ }^{\circ} \mathrm{C}$. From a separate experiment with NMR monitoring, a mixture of $4 \mathbf{c}(43 \%), 4 \mathbf{a}(43 \%)$ and $4 \mathbf{b}(14 \%)$ was observed after irradiation for $1.5 \mathrm{~h}$. Further irradiation beyond this point does not significantly change the ratio of the three species. The solution was eluted with $n$ heptane through a silica gel column $(2 \times 15 \mathrm{~cm}$, prepared from heptane). A yellow fraction of 4c was collected, while the other Mo species present in solution remained trapped by the column. The solvent was removed under reduced pressure, giving a yellow-brown solid (yield $239 \mathrm{mg}, 30 \%$ ). Crystals suitable for the X-ray analysis were obtained by recrystallization of the solid in heptane at $-80{ }^{\circ} \mathrm{C}$. Anal. Calcd. for $\mathrm{C}_{12} \mathrm{H}_{16} \mathrm{Mo}$ : C, 56.25; H, 6.25. Found: C, 56.16; H, 6.36 .

(b) By thermolysis. $10 \mathrm{mg}$ of the equilibrium $\mathbf{4 a} / \mathbf{b}$ mixture was dissolved in $0.5 \mathrm{~mL}$ of $\mathrm{C}_{6} \mathrm{D}_{6}$ in an NMR tube, which was then flame-sealed and heated to $100^{\circ} \mathrm{C}$ for $2.5 \mathrm{~h}$. NMR monitoring showed the formation of a mixture of $4 \mathbf{c}$ and $4 \mathbf{a}$ in ca. 1:1 ratio. No $4 \mathbf{b}$ was detected in this experiment. Prolonged heating resulted in decomposition.

Photolysis of compound $4 c . \mathrm{A} \mathrm{C}_{6} \mathrm{D}_{6}$ solution of $\mathbf{4 c}(10 \mathrm{mg}$ in $0.5 \mathrm{~mL})$ in an NMR tube was placed in water bath and irradiated for $1.5 \mathrm{~h}$. The temperature of the bath remained below $40^{\circ} \mathrm{C}$ during photolysis. NMR monitoring showed the formation of a mixture of $4 \mathbf{c}(62$ $\%), 4 a(20 \%)$ and $\mathbf{4 b}(18 \%)$, accompanying unidentified decomposition products.

Thermolysis of compound 4c. $10 \mathrm{mg}$ of $4 \mathbf{c}$ was dissolved in $0.5 \mathrm{~mL}$ of $\mathrm{C}_{6} \mathrm{D}_{6}$ in an NMR tube, which was then flame sealed and heated to $100^{\circ} \mathrm{C}$ for $1 \mathrm{~h}$. NMR monitoring showed the formation of a mixture of $\mathbf{4 c}$ and $\mathbf{4 a}$ in ca. 1:1 ratio. No $\mathbf{4 b}$ was detected in this experiment. 
Preparation of $\left[\mathrm{CpMo}\left(\right.\right.$ supine $\left.-\eta-\mathrm{C}_{3} \mathrm{H}_{5}\right)\left(\right.$ supine $\left.\left.-\eta-\mathrm{C}_{4} \mathrm{H}_{6}\right)\right]\left[\mathrm{PF}_{6}\right]$ (5b). To a solution of $\mathrm{CpMo}\left(\eta^{3}-\mathrm{C}_{3} \mathrm{H}_{5}\right)\left(\eta^{4}-\mathrm{C}_{4} \mathrm{H}_{6}\right)(4 \mathbf{a}$ and $4 \mathbf{b})(486 \mathrm{mg}, 1.90 \mathrm{mmol})$ in $10 \mathrm{~mL}$ of $\mathrm{CH}_{2} \mathrm{Cl}_{2}$ was added a solution of $\mathrm{FcPF}_{6}(629 \mathrm{mg}, 1.90 \mathrm{mmol})$ in $\mathrm{CH}_{2} \mathrm{Cl}_{2}(230 \mathrm{~mL})$, resulting in the precipitation of a green crystalline solid. After $2 \mathrm{~h}$, the solid was filtered off, washed with $5 \mathrm{~mL}$ heptane, and dried under vacuum (yield $455 \mathrm{mg}, 60 \%$ ). This crude material is a mixture of two isomers (5a and $\mathbf{5 b}$, see Results Section). The solubility of the green solid is very poor in THF, chlorinated solvents (dichloromethane or 1,1,2-trichloroethane) or aromatic solvent (benzene or toluene). The compound has a higher solubility in acetone, giving red-violet solution of $\mathbf{5 b}$. Dark violet crystals of $\mathbf{5 b}$ were obtained from the concentrated acetone solutions by cooling to $-20^{\circ} \mathrm{C}$. Anal. Calcd for $\mathrm{C}_{12} \mathrm{H}_{16} \mathrm{MoPF}_{6}$ : C, 35.91; H, 3.99. Found: C, 35.69; H, 4.31. EPR $\left(\mathrm{CH}_{2} \mathrm{ClCHCl}_{2}\right): \mathrm{g}=2.028$ (septet with Mo satellites, $\left.\mathrm{a}_{\mathrm{Mo}}=33 \mathrm{G}, \mathrm{a}_{\mathrm{H}}=7 \mathrm{G}\right)$ IR (Nujol mull): $842 \mathrm{~cm}^{-1}, \mathrm{PF}_{6}$. This compound appears to be indefinitely air stable in the solid state (the crystals did not deteriorate in air for over 1 month).

Reaction of compound 5 with $\mathrm{Cp}_{2} \mathrm{Co}$. (a) From the crude 5a/b mixture. The crude $\mathbf{5 a} / \mathbf{b}$ mixture of the above preparation $(10 \mathrm{mg}, 0.025 \mathrm{mmol})$ was suspended in $20 \mathrm{~mL}$ of THF and $\mathrm{Cp}_{2} \mathrm{Co}(30 \mathrm{mg}, 0.16 \mathrm{mmol})$ was added. The mixture was stirred for $2 \mathrm{~h}$, during which time the green solid slowly disappeared to yield a red-brown solution. The suspension was evaporated to dryness under reduced pressure and the residue was extracted into $30 \mathrm{~mL}$ of $n$ heptane. The mixture was filtered and the solution was again evaporated to dryness. The redbrown residue was dissolved in $0.5 \mathrm{~mL}$ of $\mathrm{C}_{6} \mathrm{D}_{6}$. A ${ }^{1} \mathrm{H}$ NMR spectrum indicates the presence of $80 \%$ of $\mathbf{4 a}$ and $20 \%$ of $\mathbf{4 b}$ (see Table 1 and Results section). The latter compound gradually transformed into the former.

(b) From crystallized $\mathbf{5 b}$. Selective formation of $\mathbf{4 b}$. Red-violet crystalline $\mathbf{5 b}(5.0$ $\mathrm{mg}, 0.012 \mathrm{mmol})$ was suspended in $\mathrm{C}_{6} \mathrm{D}_{6}(0.5 \mathrm{~mL})$ in a thin-walled $5 \mathrm{~mm}$ NMR tube. $\mathrm{Cp}_{2} \mathrm{Co}$ ( $2.5 \mathrm{mg}, 0.013 \mathrm{mmol}$ ) was added. All the solid rapidly dissolved to yield a red solution. The ${ }^{1} \mathrm{H}-\mathrm{NMR}$ spectrum of this solution shows the presence of $\mathbf{4 b}$ and no significant amount of $\mathbf{4 a}$. Continued ${ }^{1} \mathrm{H}-\mathrm{NMR}$ monitoring of this solution revealed the isomerization of $\mathbf{4 b}$ to $\mathbf{4 a}$ with $\mathrm{t}_{1 / 2}=6.5 \mathrm{~h}$ at room temperature. 
Oxidation of compound 4c. Formation of compounds $5 \mathrm{c}$ and $5 \mathrm{~d}$. Compound $4 \mathrm{c}$ $(1.5 \mathrm{mg}, 5.9 \mu \mathrm{mol})$ and $\mathrm{Cp}_{2} \mathrm{FePF}_{6}(2.0 \mathrm{mg}, 6.0 \mu \mathrm{mol})$ were placed in a $3 \mathrm{~mm}$ Pyrex EPR tube. The addition of THF $(150 \mu \mathrm{L})$ to the tube produced a suspension. The reaction was monitored by EPR spectroscopy, indicating the formation of two new isomers of compound $\mathbf{5}(\mathrm{g}=2.000$, $\mathrm{a}_{\mathrm{H}}=6.0 \mathrm{G}$ for one isomer; $\mathrm{g}=1.986, \mathrm{a}_{\mathrm{H}}=6.0 \mathrm{G}$ for the other isomer) (see Results). 
Table 2. Crystal Data for All Compounds

\begin{tabular}{|c|c|c|}
\hline compound & $2 / 3$ & $4 a$ \\
\hline formula & $\mathrm{C}_{18} \mathrm{H}_{22} \mathrm{Br}_{1.78} \mathrm{Cl}_{0.22} \mathrm{Mo}_{2}$ & $\mathrm{C}_{12} \mathrm{H}_{16} \mathrm{Mo}$ \\
\hline fw & 580.10 & 256.19 \\
\hline space group & $P 2_{1} / c$ & $P 2_{1} / c$ \\
\hline $\mathrm{a}, \AA$ & $10.652(2)$ & $12.4437(5)$ \\
\hline $\mathrm{b}, \AA$ & $7.5072(6)$ & $7.3498(4)$ \\
\hline $\mathrm{c}, \AA$ & $11.9581(14)$ & $12.0043(5)$ \\
\hline$\beta, \operatorname{deg}$ & $110.698(8)$ & $111.927(3)$ \\
\hline $\mathrm{V}, \AA^{3}$ & $894.5(2)$ & $1018.48(8)$ \\
\hline $\mathrm{Z}$ & 2 & 4 \\
\hline $\mathrm{d}_{\mathrm{calc}}, \mathrm{g} / \mathrm{cm}^{3}$ & 2.154 & 1.671 \\
\hline$\mu(\operatorname{Mo~K} \alpha), \mathrm{mm}^{-1}$ & 5.396 & 1.236 \\
\hline $\begin{array}{l}\text { radiation (monochromated } \\
\text { in incident beam) }\end{array}$ & \multicolumn{2}{|c|}{$\operatorname{Mo} \mathrm{K} \alpha(\lambda=0.71073 \AA)$} \\
\hline temp, ${ }^{\circ} \mathrm{C}$ & $153(2) \mathrm{K}$ & $153(2))$ \\
\hline transmissn factors: $\max , \min$ & $0.1694,0.0698$ & $0.7363,0.6428$ \\
\hline \multirow[t]{2}{*}{ Final $R$ indices $[I>2 \sigma(I)]^{a, b}$} & $\mathrm{R} 1=0.0373$ & $\mathrm{R} 1=0.0163$ \\
\hline & $\mathrm{wR} 2=0.0988$ & $w R 2=0.0410$ \\
\hline no. of data $[\mathrm{I}>2 \sigma(\mathrm{I})]$ & 1533 & 1510 \\
\hline \multirow[t]{2}{*}{$\mathrm{R}$ indices (all data) $)^{\mathrm{a}, \mathrm{b}}$} & $\mathrm{R} 1=0.0379$ & $\mathrm{R} 1=0.0211$ \\
\hline & $w R 2=0.0994$ & $\mathrm{wR} 2=0.0438$ \\
\hline
\end{tabular}


Table 2. Crystal Data for All Compounds (continued)

\begin{tabular}{|c|c|c|}
\hline compound & $\mathbf{5 b}$ & $4 c$ \\
\hline formula & $\mathrm{C}_{12} \mathrm{H}_{16} \mathrm{~F}_{6} \mathrm{MoP}$ & $\mathrm{C}_{12} \mathrm{H}_{16} \mathrm{Mo}$ \\
\hline fw & 401.16 & 256.19 \\
\hline space group & $\mathrm{Cmcm}$ & Pnma \\
\hline $\mathrm{a}, \AA$ & $7.6228(5)$ & $11.9689(6)$ \\
\hline $\mathrm{b}, \AA$ & $23.336(2)$ & $11.6175(11)$ \\
\hline $\mathrm{c}, \AA$ & $7.7887(4)$ & $7.4177(6)$ \\
\hline$\beta, \operatorname{deg}$ & & \\
\hline $\mathrm{V}, \AA^{3}$ & $1385.5(2)$ & $1031.42(14)$ \\
\hline $\mathrm{Z}$ & 4 & 4 \\
\hline $\mathrm{d}_{\mathrm{calc}}, \mathrm{g} / \mathrm{cm}^{3}$ & 1.923 & 1.650 \\
\hline$\mu(\mathrm{Mo} \mathrm{K} \alpha), \mathrm{mm}^{-1}$ & 1.116 & 1.221 \\
\hline $\begin{array}{l}\text { radiation (monochromated } \\
\text { in incident beam) }\end{array}$ & \multicolumn{2}{|c|}{$\operatorname{Mo} \operatorname{K} \alpha(\lambda=0.71073 \AA)$} \\
\hline $\begin{array}{l}\text { temp, }{ }^{\circ} \mathrm{C} \\
\text { transmissn factors: } \max , \min \end{array}$ & transmissn factors: $\max , \min$ & $153(2)$ \\
\hline \multirow[t]{2}{*}{ Final $R$ indices $[I>2 \sigma(I)]^{a, b}$} & $\mathrm{R} 1=0.0375$ & $\mathrm{R} 1=0.0308$ \\
\hline & $\mathrm{wR} 2=0.0964$ & $\mathrm{wR} 2=0.0838$ \\
\hline \multicolumn{3}{|l|}{ no. of data $[\mathrm{I}>2 \sigma(\mathrm{I})]$} \\
\hline \multirow[t]{2}{*}{$\mathrm{R}$ indices (all data) $)^{\mathrm{a}, \mathrm{b}}$} & $\mathrm{R} 1=0.0379$ & $\mathrm{R} 1=0.0338$ \\
\hline & $\mathrm{wR} 2=0.0967$ & $\mathrm{wR} 2=0.0865$ \\
\hline
\end{tabular}


X-ray Crystallography. (a) Compounds 2/3. Crystal parameters, data collection, and structure refinement details are in Table 2 and in the Supporting Information. No decay correction was applied. Data were corrected for Lorentz and polarization factors and for absorption on the basis of nine $\psi$-scan reflections. Intensity statistics and systematic absences clearly determined the centrosymmetric monoclinic space group P2 $1 /$ c (no. 14). The heavy atoms $(\mathrm{Mo}, \mathrm{Br})$ were located by direct methods and all the other non-hydrogen atoms by alternate full-matrix least-squares cycles and difference-Fourier maps. After anisotropic refinement of all non-hydrogen atoms, all of the hydrogen atoms bonded to carbon atoms were placed in calculated positions. Only the hydrogen atoms of the $\mathrm{C}_{4} \mathrm{H}_{6}$ group were allowed to refine freely. At this point, one residual peak in the difference Fourier was well above background (1.24 e. $\left.\AA^{-3}\right)$ and lay approximately $1.44 \AA$ from $\mathrm{C}(9)$ and nearly $1.80 \AA$ from $\mathrm{C}(6)$. It was clearly asymmetric between these two atoms and believed to be a portion of a partial occupancy $\mathrm{C}_{4} \mathrm{H}_{6}$ group that overlapped with the major group in nearly the same location. Two $\mathrm{C}_{4} \mathrm{H}_{6}$ groups were now input with instructions to refine their respective occupancies: atoms $\mathrm{C}(6)-\mathrm{C}(7)-\mathrm{C}(8)-\mathrm{C}(9)$ of the major orientation and atoms $\mathrm{C}(7 \mathrm{~A})-\mathrm{C}(8 \mathrm{~A})-\mathrm{C}(9 \mathrm{~A})-\mathrm{C}(10 \mathrm{~A})$ of the second orientation, arranged in such a way that the $C(7) / C(7 A), C(8) / C(8 A)$, and $C(9) / C(9 A)$ pairs were on the same site. Refinement with the proper occupancy constraints (see Supporting information), yielded a 0.8851:0.1149 ratio for the two orientations and $\mathrm{R}(\mathrm{F})=4.05 \%, \mathrm{wR}\left(\mathrm{F}^{2}\right)$ $=10.90 \%$ and $\mathrm{GOF}=1.149$ for all data. Since NMR evidence gives conclusive indication of a mixture of dibromo 2 (major) and chlorobromo 3 (minor) mixture, a $\mathrm{Br} / \mathrm{Cl}$ disorder model was also introduced for the two bridging atoms and the $\mathrm{Br}: \mathrm{Cl}$ ratio was found to converge to 0.888:0.112, with improvement of the final agreement figures (see Table 2). A final differenceFourier map was essentially featureless with the largest peaks, $|\Delta \rho| \leq 1.095 \mathrm{e}^{-3}$, in the vicinity of the $\operatorname{Mo}(1)$ or $\operatorname{Br}(1)$ atoms. Selected bond distances and angles are listed in Table 3.

Table 3. Selected bond distances $(\AA)$ and angles $\left(^{\circ}\right)$ for the structure of $\mathbf{2} / \mathbf{3}$.
$\operatorname{Mo}(1)-\operatorname{Br}(1)^{\mathrm{a}}$
2.6613(6)
$\operatorname{Mo}(1)-C(9)$
$2.215(10)$
$\operatorname{Mo}(1)-\operatorname{Br}(1)^{\# \mathrm{a}}$
2.6570(6)
$\mathrm{Mo}(1)-\mathrm{C}(10 \mathrm{~A})$
Mo(1)-C(1)
$2.308(5)$
$\mathrm{C}(1)-\mathrm{C}(2)$
$1.396(8)$ 


$\begin{array}{llll}\mathrm{Mo}(1)-\mathrm{C}(2) & 2.361(5) & \mathrm{C}(1)-\mathrm{C}(5) & 1.419(8) \\ \mathrm{Mo}(1)-\mathrm{C}(3) & 2.301(5) & \mathrm{C}(2)-\mathrm{C}(3) & 1.393(8) \\ \mathrm{Mo}(1)-\mathrm{C}(4) & 2.213(5) & \mathrm{C}(3)-\mathrm{C}(4) & 1.419(9) \\ \mathrm{Mo}(1)-\mathrm{C}(5) & 2.209(5) & \mathrm{C}(4)-\mathrm{C}(5) & 1.446(9) \\ \operatorname{Mo}(1)-\mathrm{CNT} T^{\mathrm{b}} & 1.936(5) & \mathrm{C}(6)-\mathrm{C}(7) & 1.440(8) \\ \operatorname{Mo}(1)-\mathrm{C}(6) & 2.246(5) & \mathrm{C}(7)-\mathrm{C}(8) & 1.371(10) \\ \operatorname{Mo}(1)-\mathrm{C}(7) & 2.332(5) & \mathrm{C}(8)-\mathrm{C}(9) & 1.425(10) \\ \operatorname{Mo}(1)-\mathrm{C}(8) & 2.31(2) & \mathrm{C}(9 \mathrm{~A})-\mathrm{C}(109 \mathrm{~A}) & 1.45(3)\end{array}$

$\begin{array}{llll}\operatorname{Br}(1)-\operatorname{Mo}(1)-\operatorname{Br}(1)^{\# a} & 79.74(2) & \mathrm{C}(2)-\mathrm{C}(1)-\mathrm{C}(5) & 105.2(5) \\ \operatorname{Br}(1)-\operatorname{Mo}(1)-\mathrm{CNT}{ }^{\mathrm{a}, \mathrm{b}} & 111.9(2) & \mathrm{C}(1)-\mathrm{C}(2)-\mathrm{C}(3) & 110.5(5) \\ \operatorname{Br}(1)^{\#-M o}(1)-\mathrm{CNT}{ }^{\mathrm{a}, \mathrm{b}} & 112.4(2) & \mathrm{C}(2)-\mathrm{C}(3)-\mathrm{C}(4) & 109.6(5) \\ \mathrm{CNT}-\mathrm{Mo}(1)-\mathrm{X}(67)^{\mathrm{b}} & 127.3(2) & \mathrm{C}(3)-\mathrm{C}(4)-\mathrm{C}(5) & 103.9(5) \\ \mathrm{CNT}-\mathrm{Mo}(1)-\mathrm{X}(89)^{\mathrm{b}} & 129.4(2) & \mathrm{C}(1)-\mathrm{C}(5)-\mathrm{C}(4) & 110.8(5) \\ \mathrm{Mo}(1)-\operatorname{Br}(1)-\mathrm{Mo}(1)^{\# \mathrm{a}} & 100.26(2) & \mathrm{C}(6)-\mathrm{C}(7)-\mathrm{C}(8) & 117.9(6) \\ & & \mathrm{C}(7)-\mathrm{C}(8)-\mathrm{C}(9) & 118.7(6)\end{array}$

${ }^{a}$ Disordered $\mathrm{Br} / \mathrm{Cl}$ site (0.888:0.112). ${ }^{\mathrm{b}} \mathrm{CNT}=$ centroid of $\mathrm{C}(1)$ through $\mathrm{C}(5)$ atoms. $\mathrm{X}(\mathrm{nm})$ $=$ center point of the $\mathrm{C}(\mathrm{n})-\mathrm{C}(\mathrm{m})$ bond.

(b) Compound 4a. All operations were conducted as detailed above for compound 2/3. No decay correction was necessary. Intensity statistics and systematic absences clearly determined the centrosymmetric monoclinic space group P2 1 /c (no. 14). The structure was determined by direct methods with the successful location of the heavy atom (Mo) and several carbon atoms. Refinement was conducted as described in the previous paragraph, including the treatment of hydrogen atoms. A final difference-Fourier map was essentially featureless with the largest peaks, $|\Delta \rho| \leq 0.257 \mathrm{e} \cdot \AA^{-3}$. Crystal and refinement parameters are collected in Table 2, while selected bond distances and angles are listed in Table 4.

Table 4. Selected bond distances $(\AA)$ and angles $\left(^{\circ}\right)$ for the structure of $\mathbf{4 a}$. 


\begin{tabular}{|c|c|c|c|}
\hline $\operatorname{Mo}(1)-C(1)$ & $2.314(2)$ & $\operatorname{Mo}(1)-C(12)$ & $2.261(2)$ \\
\hline $\operatorname{Mo}(1)-C(2)$ & $2.299(2)$ & $C(1)-C(2)$ & $1.417(3)$ \\
\hline $\operatorname{Mo}(1)-C(3)$ & $2.321(2)$ & $C(1)-C(5)$ & $1.392(3)$ \\
\hline $\mathrm{Mo}(1)-\mathrm{C}(4)$ & $2.338(2)$ & $C(2)-C(3)$ & $1.415(3)$ \\
\hline $\operatorname{Mo}(1)-C(5)$ & $2.333(2)$ & $C(3)-C(4)$ & $1.382(3)$ \\
\hline Mo-CNTa & $1.997(2)$ & $\mathrm{C}(4)-\mathrm{C}(5)$ & $1.390(3)$ \\
\hline $\operatorname{Mo}(1)-C(6)$ & $2.294(2)$ & $C(6)-C(7)$ & $1.415(3)$ \\
\hline $\operatorname{Mo}(1)-C(7)$ & $2.211(2)$ & $C(7)-C(8)$ & $1.407(3)$ \\
\hline $\operatorname{Mo}(1)-C(8)$ & $2.300(2)$ & $C(9)-C(10)$ & $1.411(3)$ \\
\hline $\operatorname{Mo}(1)-C(9)$ & $2.266(2)$ & $\mathrm{C}(10)-\mathrm{C}(11)$ & $1.381(3)$ \\
\hline $\operatorname{Mo}(1)-C(10)$ & $2.330(2)$ & $\mathrm{C}(11)-\mathrm{C}(12)$ & $1.416(3)$ \\
\hline $\operatorname{Mo}(1)-C(11)$ & $2.327(2)$ & & \\
\hline CNT-Mo(1)-C(6) ${ }^{a}$ & $118.7(1)$ & CNT-Mo(1)-X(910) ${ }^{a}$ & $126.4(1)$ \\
\hline CNT-Mo(1)-C(7) ${ }^{a}$ & $108.5(1)$ & CNT-Mo(1)-C(11) ${ }^{a}$ & $143.8(1)$ \\
\hline CNT-Mo(1)-C(8) ${ }^{a}$ & $120.2(1)$ & CNT-Mo(1)-C(12) ${ }^{a}$ & $109.0(1)$ \\
\hline CNT-Mo(1)-X(67) ${ }^{a}$ & $114.9(1)$ & CNT-Mo(1)-X(1112) ${ }^{a}$ & $126.8(1)$ \\
\hline CNT-Mo(1)-X(78) ${ }^{a}$ & $115.7(1)$ & $C(6)-C(7)-C(8)$ & $122.5(2)$ \\
\hline CNT-Mo(1)-C(9) ${ }^{a}$ & $108.7(1)$ & $C(9)-C(10)-C(11)$ & $120.8(2)$ \\
\hline CNT-Mo(1)-C(10) ${ }^{a}$ & $143.4(1)$ & $\mathrm{C}(10)-\mathrm{C}(11)-\mathrm{C}(12)$ & $120.7(2)$ \\
\hline
\end{tabular}

${ }^{a} \mathrm{CNT}=$ centroid of $\mathrm{C}(1)$ through $\mathrm{C}(5)$ atoms. $\mathrm{X}(\mathrm{nm})=$ center point of the $\mathrm{C}(\mathrm{n})-\mathrm{C}(\mathrm{m})$ vector.

(c) Compound 5b. All operations were carried out as described above for compounds 2/3. No decay correction was necessary. Systematic absences indicated one of three possible space groups, with intensity statistics favoring the noncentrosymmetric choices: $C m c 2_{1}$ (no.36, $\mathrm{CFOM}=1.28$ ), $A m a 2$ (no.40, $\mathrm{CFOM}=4.86$ ), or $\mathrm{Cmcm}$ (no. 63, $\mathrm{CFOM}=8.23$ ).

A satisfactory refinement was achieved in all three space groups (see full details in the Supporting Information): $\mathrm{R}(\mathrm{F})=2.88 \%$ in $\mathrm{Cmc} 2_{1}, 3.38 \%$ in $\mathrm{Ama2}$, and $3.79 \%$ in $\mathrm{Cmcm}$. The 
centrosymmetric choice is believed to be the correct one. The molecule sits on a special position, creating symmetry-related disorder, in all space groups (more severely so in the centrosymmetric one), thus a complex set of constraints was required to allow proper convergence of the structure. Full details of the structure refinement in the various groups are available in the Supporting Information. A final difference-Fourier map was essentially featureless with the largest peak having $|\Delta \rho|=1.13 \mathrm{e} \cdot \AA^{-3}$ within the $\mathrm{PF}_{6}$ counterion and $|\Delta \rho|=$ $0.44 \mathrm{e} \cdot \AA^{-3}$ within the cation. Crystal and refinement parameters are collected in Table 2. No table of distances and angles are reported because the severe disorder and the extensive use of restraints makes these data void of chemical significance. These data are, however, available in the Supporting Information.

(d) Compound 4c. All operations were conducted as detailed above for compound 2/3. No decay correction was necessary. Systematic absences indicated the centrosymmetric space group Pnma (no. 62) or the non-centrosymmetric space group Pna2 ${ }_{1}$ (no.33), and intensity statistics clearly favored the centric case. The structure was solved by direct methods with the successful location of the Mo and several $\mathrm{C}$ atoms. Refinement was conducted as described in the previous paragraph, including the treatment of hydrogen atoms. Since the molecule lies on a mirror plane with the allyl and diene ligands occupying general positions, these ligands were found to be interpenetrating. The $s$-trans- butadiene atoms $\mathrm{C}(6), \mathrm{C}(7), \mathrm{C}(8)$ and $\mathrm{C}(9)$ and the allyl atoms $\mathrm{C}(10), \mathrm{C}(11)$ and $\mathrm{C}(12)$ were all refined at half occupancy without restraints on the atomic positions or bond lengths, but the pairs of atoms from different ligands in proximity of each other [i.e. $\mathrm{C}(9)$ and $\mathrm{C}(12)$; $\mathrm{C}(8)$ and $\mathrm{C}(11)$; and $\mathrm{C}(7)$ and $\mathrm{C}(10)$ ] were refined with a common thermal parameter. The final sorting of which atom belongs to which ligand was arbitrarily made following the criterion of having similar distances for chemically analogous bonds [i.e. $\mathrm{C}(6)-\mathrm{C}(7)$ and $\mathrm{C}(8)-\mathrm{C}(9)$; $\mathrm{C}(10)-\mathrm{C}(11)$ and $\mathrm{C}(11)-\mathrm{C}(12)$ ] and angles [i.e. $\mathrm{C}(6)-\mathrm{C}(7)-\mathrm{C}(8)$ and $\mathrm{C}(7)-\mathrm{C}(8)-\mathrm{C}(9)$ ]. A final difference-Fourier map was essentially featureless with the largest peak near the heavy atom, within $1 \AA$, with $|\Delta \rho| \leq 1.38 \mathrm{eA}^{-3}$; the largest other peak had $|\Delta \rho| \leq 0.78 \mathrm{eA}^{-3}$. Crystal and refinement parameters are collected in Table 2, while selected bond distances and angles are listed in Table 5. 
Table 5. Selected bond distances $(\AA)$ and angles $\left(^{\circ}\right)$ for the structure of $\mathbf{4 c}$.

$\begin{array}{llll}\mathrm{Mo}(1)-\mathrm{CNT}^{a} & 2.009(5) & \mathrm{C}(1)-\mathrm{C}(2) & 1.411(4) \\ \mathrm{Mo}(1)-\mathrm{C}(1) & 2.318(5) & \mathrm{C}(2)-\mathrm{C}(3) & 1.395(5) \\ \mathrm{Mo}(1)-\mathrm{C}(2) & 2.340(3) & \mathrm{C}(3)-\mathrm{C}(3)^{\#} & 1.397(6) \\ \mathrm{Mo}(1)-\mathrm{C}(3) & 2.341(3) & \mathrm{C}(6)-\mathrm{C}(6)^{\#} & 1.52(2) \\ \mathrm{Mo}(1)-\mathrm{C}(6) & 2.264(7) & \mathrm{C}(6)-\mathrm{C}(7) & 1.37(2) \\ \mathrm{Mo}(1)-\mathrm{C}(7) & 2.20(3) & \mathrm{C}(7)-\mathrm{C}(8) & 1.40(2) \\ \mathrm{Mo}(1)-\mathrm{C}(8) & 2.30(4) & \mathrm{C}(8)-\mathrm{C}(9) & 1.29(3) \\ \operatorname{Mo}(1)-\mathrm{C}(9) & 2.29(4) & \mathrm{C}(10)-\mathrm{C}(11) & 1.46(2) \\ \operatorname{Mo}(1)-\mathrm{C}(10) & 2.28(3) & \mathrm{C}(11)-\mathrm{C}(12) & 1.44(3) \\ \operatorname{Mo}(1)-\mathrm{C}(11) & 2.23(4) & & \end{array}$

$\begin{array}{llll}\text { CNT-Mo(1)-X(67)a } & 120.2(4) & \mathrm{C}(1)-\mathrm{C}(2)-\mathrm{C}(3) 107.1(3) & \\ \text { CNT-Mo(1)-X(89)a } & 124.2(5) & \mathrm{C}(2)-\mathrm{C}(3)-\mathrm{C}(3)^{\#} & 108.7(2) \\ \text { CNT-Mo(1)-C(10)a } & 113.5(3) & \mathrm{C}(7)-\mathrm{C}(6)-\mathrm{C}(6)^{\#} & 134.6(11) \\ \text { CNT-Mo(1)-C(11)a } & 141.1(6) & \mathrm{C}(6)-\mathrm{C}(7)-\mathrm{C}(8) 125(2) & \\ \text { CNT-Mo(1)-C(12)a } & 115.6(4) & \mathrm{C}(7)-\mathrm{C}(8)-\mathrm{C}(9) 120(2) & \\ \mathrm{C}(2)-\mathrm{C}(1)-\mathrm{C}(2)^{\#} & 108.5(4) & \mathrm{C}(10)-\mathrm{C}(11)-\mathrm{C}(12) & 108.6(13)\end{array}$

${ }^{a} \mathrm{CNT}=$ centroid of $\mathrm{C}(1)$ through $\mathrm{C}(3)$ and symmetry related atoms. $\mathrm{X}(\mathrm{nm})=$ center point of the $\mathrm{C}(\mathrm{n})-\mathrm{C}(\mathrm{m})$ vector.

\section{Results and Discussion}

(a) Syntheses and NMR characterization of Mo(II) compounds. Compound $\mathrm{CpMoCl}_{2}\left(\eta-\mathrm{C}_{4} \mathrm{H}_{6}\right)(\mathbf{1})$ has previously been prepared by the interaction of $\mathrm{CpMoCl}\left(\mathrm{CF}_{3} \mathrm{C} \equiv\right.$ $\left.\mathrm{CCF}_{3}\right)_{2}$ with butadiene, ${ }^{14,15}$ this methodology being limited to a maximum theoretical yield of $50 \%$. The availability of $\mathrm{CpMoCl}_{2}$ as starting material ${ }^{13}$ has allowed us to directly prepare complex 1 according to eq 1 in yields up to $90 \%$. 


$$
\mathrm{CpMoCl}_{2}+\mathrm{C}_{4} \mathrm{H}_{6} \stackrel{2}{2} \stackrel{\mathrm{THF}}{\longrightarrow} \mathrm{CpMoCl}_{2}\left(\mathrm{C}_{4} \mathrm{H}_{6}\right)
$$

Treatment of a THF suspension of compound 1 with one equiv of allylmagnesiumbromide at $-78^{\circ} \mathrm{C}$ produces compound $\left[\mathrm{CpMo}\left(\eta-\mathrm{C}_{4} \mathrm{H}_{6}\right)(\mu-\mathrm{Br})\right]_{2}(2)$, accompanied by a small amount of $\mathrm{Cp}_{2} \mathrm{Mo}_{2}\left(\eta-\mathrm{C}_{4} \mathrm{H}_{6}\right)_{2}(\mu-\mathrm{Br})(\mu-\mathrm{Cl})(3)$, see eq. 2. The chemical and structural nature of the isolated material is confirmed by ${ }^{1} \mathrm{H}-\mathrm{NMR}$ spectroscopy and X-ray crystallography (vide infra). In addition, the nature of the major component as a bromo instead of chloro derivative is established by a low-resolution anionic mass spectrum, which clearly exhibits the bromide mass peaks at $\mathrm{M}=79$ and 81 with 1:1 isotopic pattern as the most intense peaks in the spectrum. The chloride anion was not detected in the mass spectrum, presumably due to low concentration $\left(\mathrm{Br}: \mathrm{Cl}=\right.$ 93:7 mole/mole as derived from ${ }^{1} \mathrm{H}-\mathrm{NMR}$, vide infra).

$$
\begin{aligned}
& \mathrm{CpMoCl}_{2}\left(\mathrm{C}_{4} \mathrm{H}_{6}\right) \stackrel{\mathrm{C}_{3} \mathrm{H}_{5} \mathrm{MgBr}}{\longrightarrow} \quad\left[\mathrm{CpMo}(\mu-\mathrm{Br})\left(\mathrm{C}_{4} \mathrm{H}_{6}\right)\right]_{2}+\mathrm{Cp}_{2} \mathrm{Mo}_{2}(\mu-\mathrm{Br})(\mu-\mathrm{Cl})\left(\mathrm{C}_{4} \mathrm{H}_{6}\right)_{2} \\
& \text { 2, major }(86 \%) \quad 3 \text {, minor }(14 \%)
\end{aligned}
$$

In a $\mathrm{C}_{6} \mathrm{D}_{6}$ solution, both compounds 2 and 3 give rise to two isomers in a 1:1 ratio. This is attributed to the possible arrangement of the individual $\mathrm{CpMo}\left(\mathrm{C}_{4} \mathrm{H}_{6}\right)$ moieties in a relative anti (I) or syn (II) fashion. The ${ }^{1} \mathrm{H}-\mathrm{NMR}$ resonances are attributed to the various compounds (2a, $\mathbf{2 b}, \mathbf{3 a}$, and $\mathbf{3 b}$ ) as shown in Table 1. Each species is characterized by a single $\mathrm{Cp}$ resonance, whereas the butadiene ligands give rise, as expected, to only three resonances for both isomers of $\mathbf{2}$ and six for both isomers of $\mathbf{3}$. Integration of the $\mathrm{Cp}$ resonances gives an overall ratio $\mathbf{2} / \mathbf{3}=86: 14$. The assignment of the resonances of $\mathbf{3}$ to a mixed-halide bridged compound is further confirmed by the result of a halide exchange experiment: treatment of the 2/3 mixture with an excess of $\mathrm{PPN}^{+} \mathrm{Cl}^{-}$results in an increase of the ${ }^{1} \mathrm{H}-\mathrm{NMR}$ resonances attributed to compound 3 (eq. 3). 


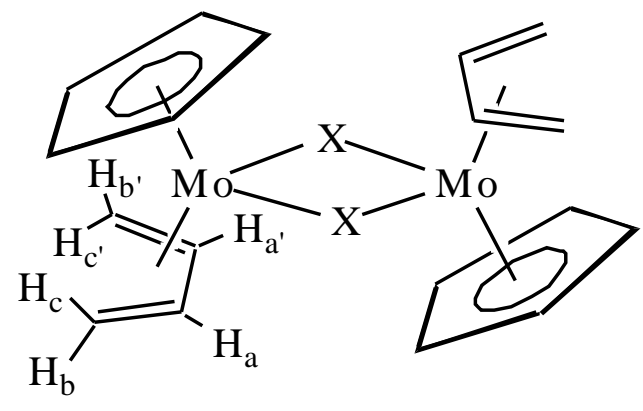

I

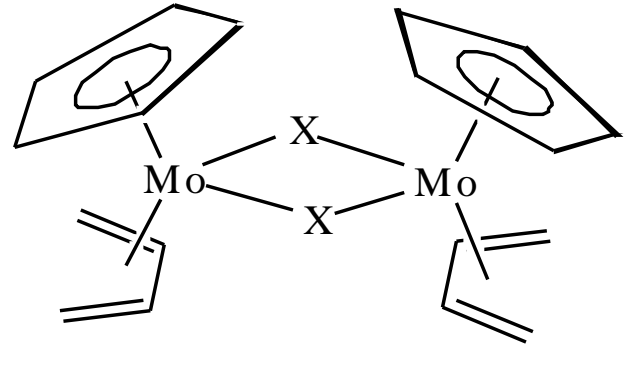

II

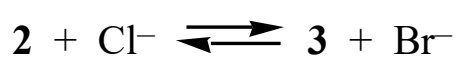

The assignment of the resonances of species $2 \mathbf{a}$ to the anti isomer and those of species $\mathbf{2 b}$ to the syn isomer, rather than the opposite, is based on the dissolution and immediate NMR investigation of crystals of the compound, which is shown by X-ray crystallography to have the anti configuration, in toluene- $d^{8}$ at $0^{\circ} \mathrm{C}$. The spectrum shows the dominant signals of species $2 \mathbf{a}(\mathbf{2 a}: \mathbf{2} \mathbf{b}=2: 1)$, but the ratio rapidly evolves to the equilibrium ratio of $1: 1$ at room temperature, indicating that (i) the two isomers have essentially the same energy, and (ii) the interconversion between the two isomers is quite facile. The assignment of the $\mathbf{3 a}$ and $\mathbf{3 b}$ sets of resonances to the anti and syn isomers, respectively, follows that of species $\mathbf{2 a}$ and $\mathbf{2 b}$, with the most downfield shifted set of resonances assigned to the anti isomer and the most upfield shifted one assigned to the syn isomer. There is a greater dependence of the chemical shifts on the configuration (anti vs. syn) than on the nature of the halogen bridges ( $\mathbf{2}$ vs. $\mathbf{3}$ ), see Table 1. Because of extensive overlap between the resonances of the various compounds, a complete assignment was only possible following a 2D-COSY NMR experiment ${ }^{16}$ (Supplemental Figure 1). The nomenclature of the butadiene $\mathrm{H}$ and $\mathrm{C}$ atoms in Table 1 follows I. All butadiene resonances are first order, well resolved doublets of doublets of doublets for the isomers of $\mathbf{3}$, while all are unresolved multiplets for the isomers of $\mathbf{2}$.

Direct reaction of 1 with two equiv of allylmagnesium bromide (eq. 4), or reaction of $2 / 3$ with one equiv of the same reagent (eq. 5), yields the allyl-butadiene complex [CpMo( $\eta$ $\left.\left.\mathrm{C}_{3} \mathrm{H}_{5}\right)\left(\eta-\mathrm{C}_{4} \mathrm{H}_{6}\right)\right]$ (4). Solutions of complex $\mathbf{4}$ show two isomers, $\mathbf{4 a}$ and $\mathbf{4} \mathbf{b}$, in an equilibrium 98:2 ratio by ${ }^{1} \mathrm{H}-\mathrm{NMR}$. These isomers differ in the relative orientation of the allyl ligand with 
respect to cyclopentadienyl ring (vide infra). A procedure for the selective generation of $\mathbf{4 b}$ will be shown later. The assignment of the ${ }^{1} \mathrm{H}-\mathrm{NMR}$ resonances and the ligand orientations for the major isomer 4a (prone for the allyl ligand; supine for the butadiene ligand; see Table 1 and refer to III for the nomenclature) have been confirmed by homonuclear decoupling experiments and NOE difference NMR experiments. In particular, an NOE effect was detected upon irradiation of $\mathrm{H}_{\mathrm{a}}$ on $\mathrm{H}_{\mathrm{b}}$ and $\mathrm{H}_{\mathrm{f}}$, of $\mathrm{H}_{\mathrm{b}}$ on $\mathrm{H}(\mathrm{Cp})$ and $\mathrm{H}_{\mathrm{c}}$, of $\mathrm{H}_{\mathrm{c}}$ on $\mathrm{H}(\mathrm{Cp})$ and $\mathrm{H}_{\mathrm{b}}$, of $\mathrm{H}_{\mathrm{d}}$ on $\mathrm{H}(\mathrm{Cp})$ and $\mathrm{H}_{\mathrm{e}}$, of $\mathrm{H}_{\mathrm{e}}$ on $\mathrm{H}_{\mathrm{d}}$ and $\mathrm{H}_{\mathrm{f}}$, and of $\mathrm{H}_{\mathrm{f}}$ on $\mathrm{H}_{\mathrm{d}}$ and $\mathrm{H}_{\mathrm{e}}$. Irradiation of the $\mathrm{Cp}$ protons does not significantly affect the other resonances.

$$
\begin{aligned}
& \mathrm{CpMoCl}_{2}\left(\eta-\mathrm{C}_{4} \mathrm{H}_{6}\right) \stackrel{2 \mathrm{C}_{3} \mathrm{H}_{5} \mathrm{MgBr}}{\underset{-\mathrm{C}_{3} \mathrm{H}_{5} \cdot \mathrm{MgClBr}}{\longrightarrow}} \mathrm{CpMo}\left(\eta-\mathrm{C}_{3} \mathrm{H}_{5}\right)\left(\eta-\mathrm{C}_{4} \mathrm{H}_{6}\right) \\
& {\left[\mathrm{CpMo}(\mu-\mathrm{X})\left(\eta-\mathrm{C}_{4} \mathrm{H}_{6}\right)\right]_{2} \underset{-\mathrm{MgXBr}}{\stackrel{2 \mathrm{C}_{3} \mathrm{H}_{5} \mathrm{MgBr}}{\longrightarrow}} 2 \mathrm{CpMo}\left(\eta-\mathrm{C}_{3} \mathrm{H}_{5}\right)\left(\eta-\mathrm{C}_{4} \mathrm{H}_{6}\right)}
\end{aligned}
$$

The assignment of the ${ }^{13} \mathrm{C}$ NMR signals was possible by way of a ${ }^{1} \mathrm{H}_{-}{ }^{13} \mathrm{C}-\mathrm{HMQC}$ NMR experiment (Supplemental Figure 2). ${ }^{17}$ All the ${ }^{13} \mathrm{C}$ chemical shifts appear to be in the expected region. ${ }^{18}$ The coupling constant for the butadiene terminal carbon atom $\left({ }^{1} \mathrm{~J}_{\mathrm{CH}}=154\right.$ $\mathrm{Hz}$ ) indicates an $\mathrm{sp}^{2}$ hybridization 19 and suggests a conventional butadiene ligand.

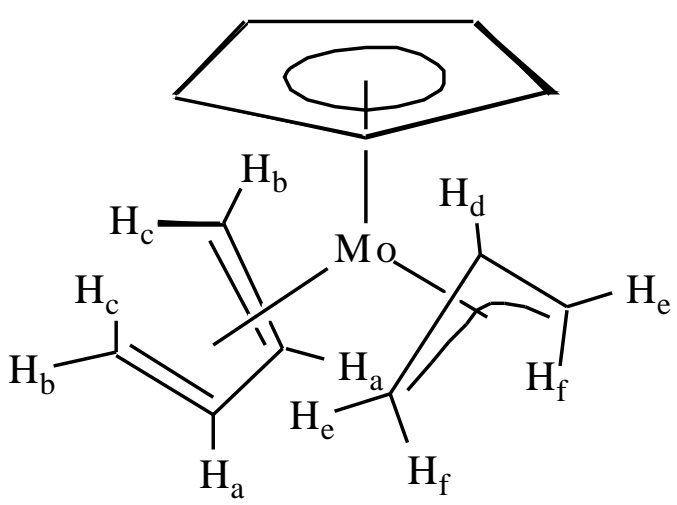

III

The assignment of the ${ }^{1} \mathrm{H}-\mathrm{NMR}$ resonances for isomer $\mathbf{4 b}$ has been confirmed by both homonuclear decoupling experiments and integration, but the orientation of the ligands (supine 
for both allyl and butadiene) could not be probed by NOE experiments. It is based on the comparison of the chemical shifts in the ${ }^{1} \mathrm{H}-\mathrm{NMR}$ spectra of $\mathbf{4 a}$ and $\mathbf{4 b}$. In particular, the protons of the butadiene ligand have approximately the same chemical shift in both isomers ( $\Delta \delta$ is 0.23 for $\mathrm{H}_{\mathrm{a}}, 0.48$ for $\mathrm{H}_{\mathrm{b}}$, and 0.25 for $\mathrm{H}_{\mathrm{c}}$ ), whereas the protons of the allyl ligand resonate in more distinct regions for the two isomers ( $\Delta \delta$ of 1.42 for $\mathrm{H}_{\mathrm{d}}, 1.03$ for $\mathrm{H}_{\mathrm{e}}$, and 0.50 for $\mathrm{H}_{\mathrm{f}}$ ). The major effect is on proton $\mathrm{H}_{\mathrm{d}}$ because this experiences a greater difference of ring current upon rearrangement from the prone to the supine configuration. In $\mathbf{4 b}$, the resonance of $\mathrm{H}_{\mathrm{d}}$ is close to that of the central butadiene proton $\left(\mathrm{H}_{\mathrm{a}}\right)$. The reliable assignment of the allyl conformation on the basis of chemical shifts has been illustrated previously. ${ }^{20,21}$ An additional interesting observation is the presence of discernible allyl geminal coupling (i.e. $\mathrm{H}_{\mathrm{e}} \mathrm{H}_{\mathrm{f}}$ ) in $\mathbf{4 a}$ but not in $\mathbf{4 b}$. The same phenomenon has previously been reported for the prone and supine isomers of $\mathrm{CpM}\left(\eta^{3}-\mathrm{C}_{3} \mathrm{H}_{5}\right)(\mathrm{CO})_{2}(\mathrm{M}=\mathrm{Mo}, \mathrm{W})$ and indenyl analogues, ${ }^{20}$ and for $\mathrm{CpM}\left(\eta^{3}-\right.$ $\left.\mathrm{C}_{3} \mathrm{H}_{5}\right)(\mathrm{CO})$ and (indenyl) $\mathrm{M}\left(\eta^{3}-\mathrm{C}_{3} \mathrm{H}_{5}\right)(\mathrm{CO})(\mathrm{M}=\mathrm{Fe}, \mathrm{Ru}) .{ }^{21,22}$ The supine-diene-supine-allyl conformation has been observed in a structurally related 16-electron complex, $[\mathrm{CpZr}(\eta-$ $\left.\left.\mathrm{C}_{3} \mathrm{H}_{5}\right)\left(\eta-\mathrm{C}_{4} \mathrm{H}_{6}\right)\right] \cdot{ }^{23}$

So long as solutions of $\mathbf{4 a} / \mathbf{b}$ remain at room temperature, no changes in the spectroscopic properties are observed over long periods of time. However, warming a $\mathrm{C}_{6} \mathrm{D}_{6}$ solution to $100^{\circ} \mathrm{C}$ in a flame sealed NMR tube, or subjecting the same solution to UV irradiation at room temperature, leads to equilibration with a third isomer, $4 \mathbf{c}$. The photolytic treatment also increases significantly the relative amount of isomer $\mathbf{4 b}$ (see Experimental). Compound $4 \mathbf{c}$ can be isolated as a pure crystalline substance because the isomerization process is frozen at room temperature and only $\mathbf{4 c}$ is sufficiently stable to withstand a chromatographic treatment on a silica gel column with $n$-heptane elution. Treatment of pure $\mathbf{4 c}$ under thermal or photolytic conditions produces mixtures of the three isomers with the same composition as obtained from the corresponding treatment of the $\mathbf{4 a / b}$ mixture. Unlike isomers $4 \mathbf{a}$ and $\mathbf{4 b}$, isomer $\mathbf{4} \mathbf{c}$ has no symmetry element, as shown by the number of resonances in the ${ }^{1} \mathrm{H}$ - and ${ }^{13} \mathrm{C}\left\{{ }^{1} \mathrm{H}\right\}$-NMR spectra (see Table 1; for the nomenclature, refer to IV). Homonuclear decoupling experiments and 2D-COSY (Supplemental Figure 3), ${ }^{13} \mathrm{C}-\mathrm{DEPT},{ }^{24}$ and ${ }^{1} \mathrm{H}-{ }^{13} \mathrm{C}$ HMQC $^{17}$ (Supplemental Figure 4) NMR experiments allow the complete assignment of all 
resonances and the formulation as $\mathrm{CpMo}\left(\right.$ supine $\left.-\eta-\mathrm{C}_{3} \mathrm{H}_{5}\right)\left(\right.$ s-trans- $\left.-\eta-\mathrm{C}_{4} \mathrm{H}_{6}\right)$, which is confirmed by an X-ray structural investigation (vide infra).

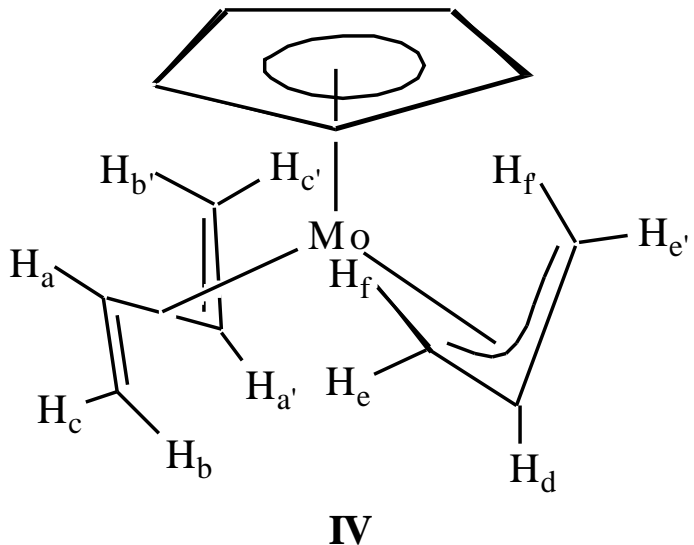

(b) Electrochemistry studies and syntheses and EPR characterization of Mo(III)

compounds. In a cyclic voltammetric investigation, the equilibrium 98:2 mixture of $\mathbf{4 a}$ and $\mathbf{4 b}$ shows a quasi-reversible oxidation process in $\mathrm{CH}_{2} \mathrm{Cl}_{2}$ at $\mathrm{E}_{1 / 2}=-0.46 \mathrm{~V}$ with respect to ferrocene (process A in Figure 1). The return wave of this process has a diminished intensity, while a second reduction wave appears at more negative potential (process B in Figure 1). A second scan shows reversibility for process $\mathbf{B}\left(\mathrm{E}_{1 / 2}=-0.87 \mathrm{~V}\right)$. A negative scan starting from $-0.73 \mathrm{~V}$ shows that wave $\mathbf{B}$ is initially absent. These observations suggest that oxidation of $\mathbf{4 a}$ yields the one-electron oxidation product, $\left[\mathrm{CpMo}\left(\text { prone- } \eta-\mathrm{C}_{3} \mathrm{H}_{5}\right)\left(\text { supine- } \eta-\mathrm{C}_{4} \mathrm{H}_{6}\right)\right]^{+}, \mathbf{5 a}$, but that this subsequently evolves relatively rapidly to another redox-active species with a lower reduction potential. A completely analogous behavior is observed in THF, the $\mathrm{E}_{1 / 2}$ values being $-0.45 \mathrm{~V}$ for $\mathbf{A}$ and $-0.85 \mathrm{~V}$ for $\mathbf{B}$. 


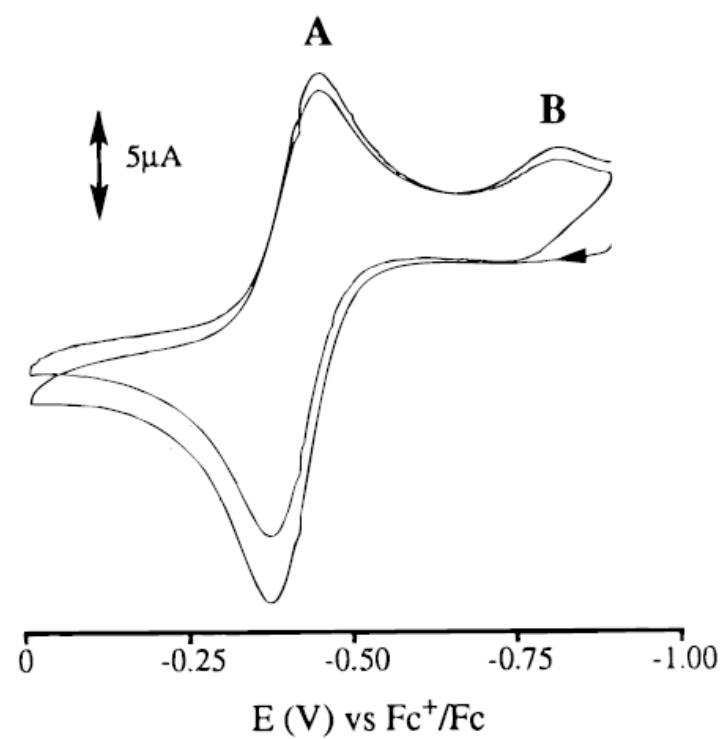

Figure 1. Room temperature cyclic voltammogram for the oxidation of $\mathbf{4 a} / \mathbf{b}$. Potentials are reported relative to the ferrocene standard. Solvent $=\mathrm{CH}_{2} \mathrm{Cl}_{2}$.

One-electron chemical oxidation of an equilibrium (98:2) solution of $\mathbf{4 a} / \mathbf{b}$ by ferrocenium hexafluorophosphate yields a green solid, equation 6. This solid is only sparingly soluble in conventional organic solvents such as THF and dichloromethane. Prolonged standing in $\mathrm{CH}_{2} \mathrm{Cl}_{2}$ led to decomposition with formation of compound $\mathbf{1}$, whereas no decomposition is observed in THF. The green solid is more soluble in acetone to yield, however, red-violet solutions. Crystallization from these solutions yield red-violet crystals that analyze correctly for the expected oxidation product, $\left[\mathrm{CpMo}\left(\eta-\mathrm{C}_{3} \mathrm{H}_{5}\right)\left(\eta-\mathrm{C}_{4} \mathrm{H}_{6}\right)\right]^{+} \mathrm{PF}_{6}{ }^{-}$. A cyclic voltammetric investigation of the red-violet crystalline product shows a reversible reduction process at $\mathrm{E}_{1 / 2}=-0.81 \mathrm{~V}$, which corresponds to process $\mathbf{B}$ for the cyclic voltammogram of $\mathbf{4}$ in Figure 1. No follow-up chemical processes are evident in the cyclic voltammogram of $\mathbf{5 b}$, indicating stability for the reduction product on the time scale of the $\mathrm{CV}$ scan. According to these results, the green solid corresponds to $\mathbf{5 a}$, whereas red-violet $\mathbf{5 b}$ is an isomer in which 5a transforms rapidly and quantitatively. By generating a dilute solution of green 5a in situ in THF and monitoring the EPR spectrum (vide infra), a complete conversion to $\mathbf{5 b}$ was observed within 1 minute at room temperature, leading to an estimation of the half life for the isomerization of $\mathrm{t}_{1 / 2}<20 \mathrm{~s}$. 
$\mathrm{CpMo}\left(\eta^{3}-\mathrm{C}_{3} \mathrm{H}_{5}\right)\left(\eta^{4}-\mathrm{C}_{4} \mathrm{H}_{6}\right)+\mathrm{Cp}_{2} \mathrm{Fe}^{+} \longrightarrow\left[\mathrm{CpMo}\left(\eta^{3}-\mathrm{C}_{3} \mathrm{H}_{5}\right)\left(\eta^{4}-\mathrm{C}_{4} \mathrm{H}_{6}\right)\right]^{+}+\mathrm{Cp}_{2} \mathrm{Fe}$

Chemical reduction of $\mathbf{5 b}$ with cobaltocene (eq. 7) yields selectively the reduction product, which is shown by NMR spectroscopy to be the pure compound $\mathbf{4 b}$, i.e. CpMo(supine$\left.\eta-\mathrm{C}_{3} \mathrm{H}_{5}\right)\left(\right.$ supine- $\left.\eta-\mathrm{C}_{4} \mathrm{H}_{6}\right)$. Compound $\mathbf{5 b}$ is therefore formulated as $[\mathrm{CpMo}($ supine- $\eta-$ $\left.\mathrm{C}_{3} \mathrm{H}_{5}\right)\left(\right.$ supine $\left.\left.-\eta-\mathrm{C}_{4} \mathrm{H}_{6}\right)\right]^{+} \mathrm{PF}_{6}-$. This stereochemistry is confirmed by a crystallographic study (vide infra). Compound $\mathbf{4 b}$ is shown by ${ }^{1} \mathrm{H}-\mathrm{NMR}$ monitoring to convert back to the equilibrium mixture of $\mathbf{4 a}$ and $\mathbf{4 b}(98: 2)$ with a $t_{1 / 2}$ of 6.5 hours at room temperature. When, on the other hand, the crude green product of eq. 4 was reduced back with cobaltocene, a 80:20 mixture of $4 \mathbf{a}$ and $\mathbf{4 b}$ was obtained, indicating that this material consists of a mixture of $\mathbf{5 a}$ and 5b. Compounds $\mathbf{4}$ and $\mathbf{5}$ therefore have different isomeric preferences, $\mathbf{4}$ being more stable with prone allyl and supine diene ligands, whereas $\mathbf{5}$ is more stable with both ligands in a supine configuration.

$\left[\mathrm{CpMo}\left(\eta^{3}-\mathrm{C}_{3} \mathrm{H}_{5}\right)\left(\eta^{4}-\mathrm{C}_{4} \mathrm{H}_{6}\right)\right]^{+}+\mathrm{Cp}_{2} \mathrm{Co} \longrightarrow \mathrm{CpMo}\left(\eta^{3}-\mathrm{C}_{3} \mathrm{H}_{5}\right)\left(\eta^{4}-\mathrm{C}_{4} \mathrm{H}_{6}\right)+\mathrm{Cp}_{2} \mathrm{Co}^{+}$

The EPR spectrum of solutions of $\mathbf{5 b}$ displays a binomial septet $\left(\mathrm{a}_{\mathrm{H}}=7 \mathrm{G}\right)$ at $\mathrm{g}=2.028$, in addition to the characteristic Mo satellites $(I=5 / 2,25 \%)$. The room temperature spectrum is not sufficiently sharp to observe all seven lines, but the resolution improved sufficiently upon cooling to $-80^{\circ} \mathrm{C}$ (see Figure 2). There may be a question concerning the possible attribution of the two outer lines of the central septet feature to the Mo satellites. To resolve this question, a simulation was performed for both the septet and the pentet models (both shown in Figure 2). Clearly, the experimental spectrum can be satisfactorily simulated only as a septet. 

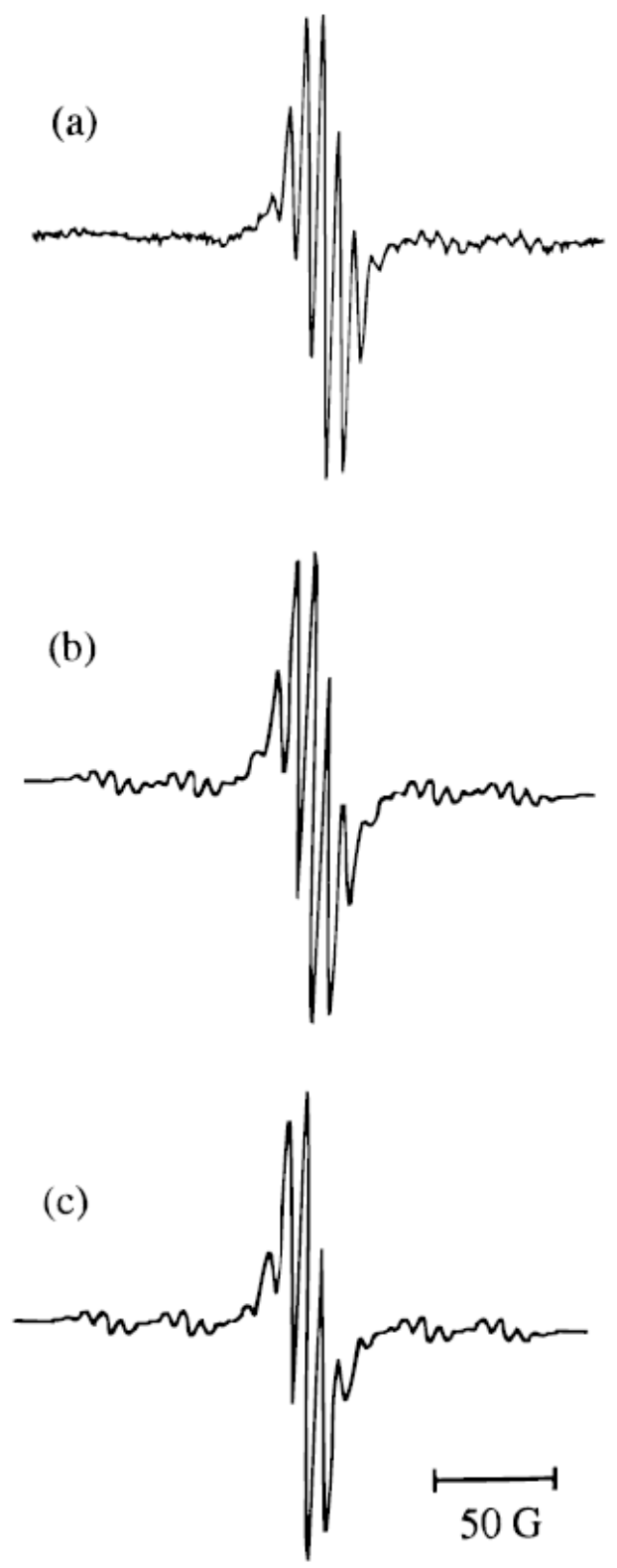

Figure 2. (a) Experimental EPR spectrum of complex $\mathbf{5 b}$ in $\mathrm{THF}$ at $\mathrm{T}=-80^{\circ} \mathrm{C}$. (b) Simulation for a system of six equivalent $\mathrm{H}$ nuclei $\left(\mathrm{a}_{\mathrm{H}}=7.0 \mathrm{G}\right.$, linewidth $=3.2$ G). (c) Simulation for a system of four equivalent $\mathrm{H}$ nuclei (same conditions as in (b)).

Compound 5a transforms too rapidly into compound $\mathbf{5 b}$ after its generation by oxidation of 4a to obtain an EPR spectrum without any signals of the more stable rearrangement product. The generation of $\mathbf{5 a}$ in $\mathrm{THF}$ at low temperature $\left(-80^{\circ} \mathrm{C}\right)$ directly in the EPR probe slows down the isomerization, however, and an initial spectrum consisting of a 
mixture of the two isomers (Figure 3(a)) can be observed. Subtraction from this spectrum of the resonance of $\mathbf{5 b}$ yields the spectrum of $\mathbf{5 a}$, which is shown in Figure 3(b). Simulation of this difference spectrum as either a septet or a pentet is shown in Figures 3(c) and 3(d), respectively. Although the spectral resolution under these conditions is not optimal, the simulation in Figure 3(c) appears closer to the experimental spectrum. Thus, it seems that the unpaired electron in this compound is strongly coupled to only four $\mathrm{H}$ nuclei $\left(\mathrm{a}_{\mathrm{H}}=8.5 \mathrm{G}, \mathrm{a}_{\mathrm{Mo}}\right.$ $=28 \mathrm{G}$, linewidth $=4 \mathrm{G})$. It is also to be noted that the 17-electron compound $\mathrm{CpMoCl}_{2}(\eta-$ $\left.\mathrm{C}_{4} \mathrm{H}_{6}\right)(\mathbf{1})$ exhibits coupling to the four terminal hydrogen atoms of the butadiene ligand $\left[\mathrm{a}_{\mathrm{H}}=\right.$ $6.64 \mathrm{G}(s y n)$ and $3.94 \mathrm{G}($ anti) $] .{ }^{14}$ On the basis of the above results, all four terminal hydrogen nuclei of the butadiene group appear to be responsible for the hyperfine splitting in both compounds $\mathbf{5 a}$ and $\mathbf{5 b}$, while the two additional $\mathrm{H}$ nuclei that are coupled with the electron in 5b are two of the four terminal $\mathrm{H}$ atoms of the allyl ligand. The EPR spectra of substituted allyl derivatives, which will be described in a later contribution, are also in agreement with these assignments. The hyperfine coupling to the different types of nuclei in $\mathbf{5 a}$ and $\mathbf{5 b}$ (Figures 2 and 3) is degenerate within the limits of the instrumental resolution.
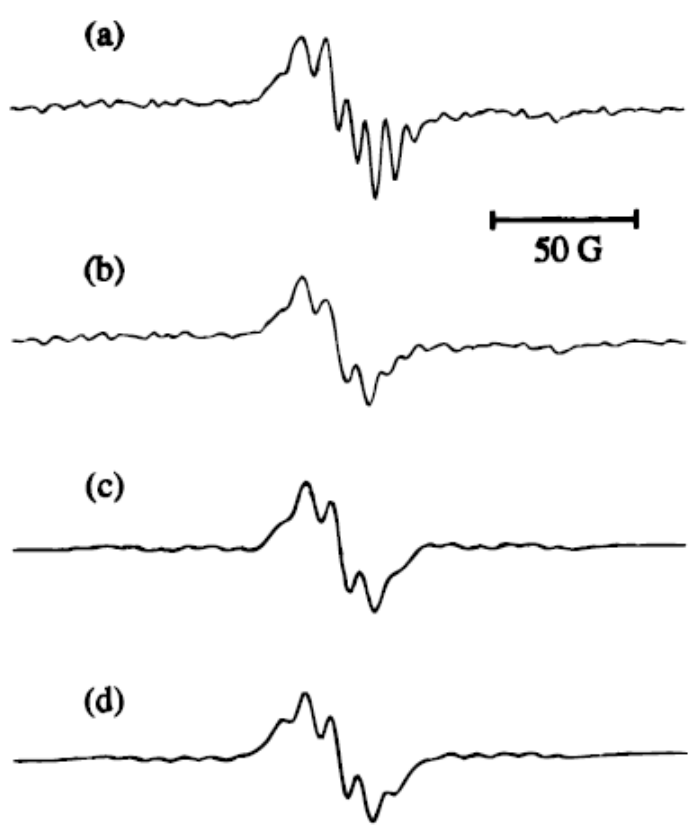

Figure 3. (a) EPR spectrum of a mixture of $\mathbf{5 a}$ and $\mathbf{5 b}$, obtained by oxidation of the $98: 2$ equilibrium mixture of $\mathbf{4 a}$ and $\mathbf{4 b}$ in $\mathrm{THF}$ at $-80^{\circ} \mathrm{C}$ (after $5 \mathrm{~min}$ ). (b) As (a), after 
substraction of the spectrum of complex $\mathbf{5 b}$. (c) Simulation for a system of four equivalent $\mathrm{H}$ nuclei $\left(\mathrm{a}_{\mathrm{H}}=8.5 \mathrm{G}, \mathrm{a}_{\mathrm{Mo}}=28 \mathrm{G}\right.$, linewidth $=4 \mathrm{G}$ ). (d) Simulation for a system of six equivalent $\mathrm{H}$ nuclei (same conditions as in (c)).

Compound $4 \mathbf{c}$ also undergoes a one-electron oxidation process. In the cyclic voltammogram, this is observed as a reversible wave at $\mathrm{E}_{1 / 2}=-0.34 \mathrm{~V}$ vs. ferrocene in $\mathrm{CH}_{2} \mathrm{Cl}_{2}$ or $-0.34 \mathrm{~V}$ in $\mathrm{THF}$, e.g. slightly less negative than the oxidation of $4 \mathbf{a}$. Of the three isomers, therefore, $\mathbf{4 c}$ is the most difficult to oxidize, whereas $\mathbf{4 b}$ is the easiest. The chemical oxidation of $\mathbf{4} \mathbf{c}$ by ferrocenium in THF initially generates solutions containing three forms of compound $\mathbf{5}$, as shown by EPR spectroscopy (Figure 4). One compound is $\mathbf{5 b}$, whereas the other two compounds are characterized by resonances at lower g values (2.000 and 1.986, respectively) showing the same hyperfine pattern as $\mathbf{5 b}\left(\mathrm{a}_{\mathrm{H}}=6.0\right.$ for both). These two species slowly disappear, leaving only $\mathbf{5 b}$ as the final EPR active compound, see Figure 4. We presume that one of these two species corresponds to the same geometry of the neutral precursor, i.e. $\left[\mathrm{CpMo}\left(\text { supine- } \eta-\mathrm{C}_{3} \mathrm{H}_{5}\right)\left(s \text {-trans- } \eta-\mathrm{C}_{4} \mathrm{H}_{6}\right)\right]^{+}, \mathbf{5 c}$. The geometry of the other species is likely to differ from that of $\mathbf{5 c}$ by the orientation of the allyl ligand, as was found for isomers $\mathbf{5 a}$ and $\mathbf{5 b}$. Thus, we assign to this final isomer the configuration $\left[\mathrm{CpMo}\left(\right.\right.$ prone- $\left.\eta-\mathrm{C}_{3} \mathrm{H}_{5}\right)($ s-trans- $\eta-$ $\left.\left.\mathrm{C}_{4} \mathrm{H}_{6}\right)\right]^{+}$, 5d. It cannot be established which isomer gives rise to which resonance in Figure 4(a): the ratio of the two resonances after immediate recording of the EPR spectrum is ca. 1:1, and does not further change during the time scale of the interconversion to $\mathbf{5 b}$. 

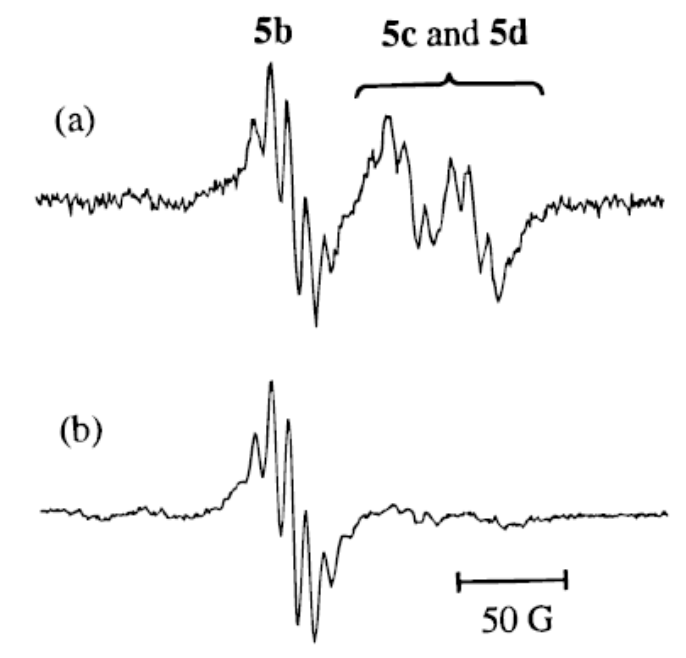

Figure 4. EPR monitoring of the oxidation of 5c with $\mathrm{Cp}_{2} \mathrm{Fe}^{+}$in THF. (a) After 10 min. (b) After $12 \mathrm{~h}$.

Unfortunately, compounds $\mathbf{5 b}, \mathbf{5 c}$ and $\mathbf{5 d}$ are only sparingly soluble in THF, thus a determination of the rate of interconversion of $\mathbf{5} \mathbf{c}$ and $\mathbf{5 d}$ to $\mathbf{5 b}$ was not possible. This is clearly illustrated by the observation of relatively constant intensities for the three species during the first part of the isomerization process. Thus, the relative intensities of the various signals is only a measure of the relative solubility of the various compounds in THF. The compounds are more soluble in acetone and $\mathrm{CH}_{2} \mathrm{Cl}_{2}$, but $\mathbf{5 c}$ and $\mathbf{5 d}$ appear to decompose in these solvents. These decomposition reactions were not further pursued.

X-ray structures. The solid state molecular structure of the $\mathbf{2 / 3}$ mixture is shown in Figure 5. The presence of both compounds as a solid solution in the crystal is suggested by the refinement of the $\mathrm{X}$-ray data. The freely refined relative occupancy of $89 \% \mathrm{Br}$ and $11 \% \mathrm{Cl}$ is in good agreement with the occupancies independently established in solution by ${ }^{1} \mathrm{H}-\mathrm{NMR}$. Obviously, such an agreement could be coincidental, since the crystal chosen for the X-ray analysis is not necessarily representative of the composition of the bulk material. The compound crystallizes in the monoclinic $P 2{ }_{1} / c$ space group, the dinuclear molecule adopting the anti arrangement. The molecule is located on an inversion center, but the ideal molecular symmetry is $\mathrm{C}_{2 \mathrm{~h}}$. The dihedral angle subtended by the Mo-C(6)-C(9) and $\mathrm{C}(6)-\mathrm{C}(7)-\mathrm{C}(8)-$ 
$\mathrm{C}(9)$ planes $(\theta)$ is $87.6(2)^{\circ}$, indicating a conventional $\eta^{4}$-s-cis-1,3-diene coordination mode. ${ }^{5}$ However, the shorter Mo-C bond length to the two lateral butadiene carbon atoms relative to two internal Mo-C distances (the average difference $\Delta \mathrm{d}$ is -0.081 ), and especially the longer butadiene lateral $\mathrm{C}-\mathrm{C}$ bond lengths relative to the central bond, suggest significant $\pi$ back bonding from the metal. 25 The $\theta$ and $\Delta \mathrm{d}$ data fit rather well the previously established correlation. ${ }^{5}$ The two metals are at $4.08 \AA$ from each other, in agreement with the absence of a direct interaction as expected from the 18-electron configuration. The analogous dimer $\left[\mathrm{CpNb}\left(\mathrm{C}_{4} \mathrm{H}_{6}\right)(\mu-\mathrm{Cl})\right]_{2}$, on the other hand, exhibits a syn rather than anti geometry. ${ }^{26}$ This difference may be related to the presence of a direct $\mathrm{Nb}-\mathrm{Nb}$ bond since this bond must be formed by overlap of the two metal $\mathrm{d}_{\mathrm{z}^{2}}$ orbitals, the local $\mathrm{z}$ axis for each metal pointing to the center of the $\mathrm{Cp}$ ligand. The supine butadiene conformation observed in $\mathbf{2 / 3}$ is ubiquitous, as precedented for the crystallographically characterized $\mathrm{CpZr}\left(\eta^{3}-\mathrm{C}_{3} \mathrm{H}_{5}\right)\left(\eta^{4}-\mathrm{C}_{4} \mathrm{H}_{6}\right),{ }^{23}$ $\mathrm{Cp} * \mathrm{HfCl}(\mathrm{py})\left(\eta^{4}-2,3-\mathrm{Me}_{2} \mathrm{C}_{4} \mathrm{H}_{4}\right),{ }^{23,27} \mathrm{CpTaX}_{2}\left(\eta^{4}-\mathrm{C}_{4} \mathrm{H}_{6}\right) \quad(\mathrm{X}=$ alkyl or halide $),{ }^{28,29}$ $\mathrm{CpMoCl}_{2}\left(\eta^{4}-\mathrm{C}_{4} \mathrm{H}_{6}\right),{ }^{14} \mathrm{CpMoI}\left[\mathrm{P}(\mathrm{OMe})_{3}\right]\left(\eta^{4}-\mathrm{CH}_{2}=\mathrm{CHCH}=\mathrm{CHCH}_{2} \mathrm{Bu}^{\mathrm{t}}\right),{ }^{30}$ and the dinuclear niobium compound $\left[\mathrm{CpNb}\left(\mathrm{C}_{4} \mathrm{H}_{6}\right)(\mu-\mathrm{Cl})\right]_{2} \cdot{ }^{26}$

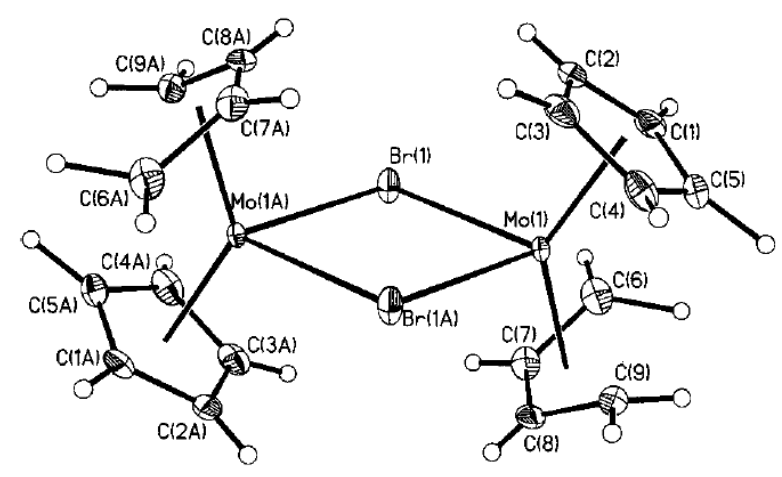

Figure 5. A view of the major component for the structure of $\mathbf{2} / \mathbf{3}$, showing the numbering scheme employed. The ellipsoids are drawn at the $30 \%$ probability level.

Crystals obtained from the equilibrium 98:2 solution of $\mathbf{4 a}$ and $\mathbf{4 b}$ exhibit the dominant solution geometry, i.e. 4a (see Figure 6). The dihedral angle of $85.4(1)^{\circ}$ between the planes of Mo- $C(9)-C(12)$ and $C(9)-C(10)-C(11)-C(12)$ is similar to that found for $\mathbf{2} / \mathbf{3}$, and the same is true for the Mo-C bond lengths to the carbon atoms of the butadiene ligand (average $\Delta \mathrm{d}=$ - 
0.065), and for the trend of butadiene $\mathrm{C}-\mathrm{C}$ bond distances. There is no apparent interligand steric hindrance, as can be seen in Figure 6. The supine orientation of the diene ligand is the ubiquitous one, as discussed above. The prone conformation of the allyl ligand is, however, less documented. A few complexes that exist in both isomeric forms in solution have been described. ${ }^{20-22}$ In the solid state, the supine orientation is observed for $\mathrm{CpMI}(\mathrm{NO})\left(\eta^{3}-\mathrm{C}_{3} \mathrm{H}_{5}\right)$ $(\mathrm{M}=\mathrm{Mo}, \mathrm{W}),{ }^{31,32} \mathrm{CpMo}\left(\eta^{3}\right.$-allyl $)\left\{\mathrm{P}(\mathrm{OMe})_{3}\right\}_{2},{ }^{30}$ and $\left(\eta^{5}-\mathrm{C}_{9} \mathrm{H}_{7}\right) \mathrm{Mo}\left(\eta^{3}-\mathrm{C}_{9} \mathrm{H}_{7}\right)(\mathrm{dppe}),{ }^{33}$ whereas the prone conformation was found for $\mathrm{CpMo}\left(\eta^{3}-\mathrm{C}_{3} \mathrm{H}_{5}\right)(\mathrm{CO})_{2} \cdot{ }^{32}$

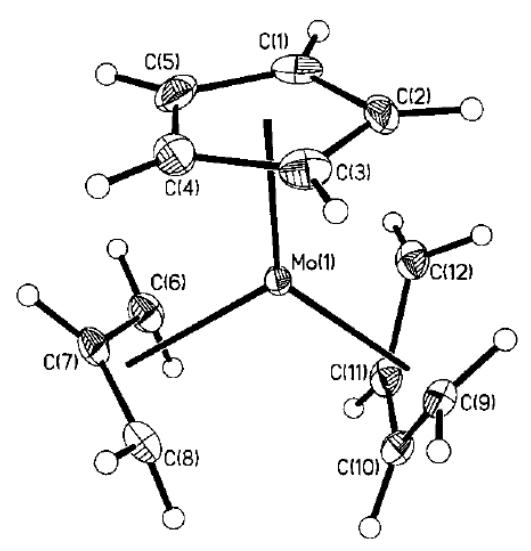

Figure 6. Molecular geometry of compound 4a with the numbering scheme employed. The ellipsoids are drawn at the $30 \%$ probability level.

For the X-ray determination of compound $\mathbf{5 b}$, disorder between the allyl and butadiene ligands and a space group ambiguity (see Experimental) do not allow the establishment of reliable metric parameters for the $\mathrm{Mo}\left(\mathrm{C}_{3} \mathrm{H}_{4}\right)\left(\mathrm{C}_{4} \mathrm{H}_{6}\right)$ moiety. The nature of the disorder, however, can only and unambiguously be modeled by the supine orientation for both allyl and diene ligands. A view of the structural model used for the refinement is shown in Figure 7. This structure is reported here only as proof of stereochemistry. Precedents for structures containing allyl or diene ligands for half sandwich $\mathrm{Mo}(\mathrm{III})$ are $\mathrm{CpMoCl}_{2}\left(\text { supine- } \eta^{4}-\mathrm{C}_{4} \mathrm{H}_{6}\right)^{14}$ and a variety of $(\mathrm{Ring}) \mathrm{Mo}\left(\text { supine }-\eta^{3}-\mathrm{C}_{3} \mathrm{H}_{5}\right)_{2}(\mathrm{Ring}=\mathrm{Cp}, 2$-methylindenyl, 2-metoxyindenyl, and 5,6-dimetoxyindenyl). 34,35 


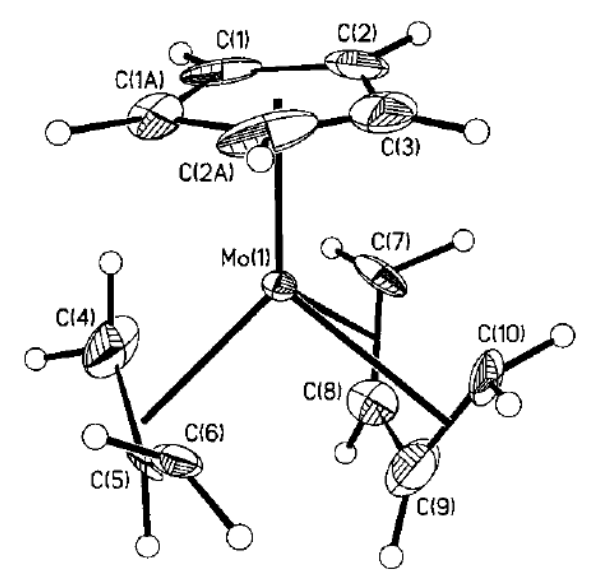

Figure 7. Molecular geometry of the cation $\mathbf{5 b}$ with the numbering scheme employed. Only one of the two possible symmetry-related orientations of the diene and allyl ligands is shown for clarity. The ellipsoids are drawn at the $30 \%$ probability level.

The X-ray structure of compound $\mathbf{4 c}$ (Figure 8) unambiguously demonstrates the $s$ trans coordination geometry for the butadiene ligand, while the allyl ligand adopts the supine orientation relative to the $\mathrm{Cp}$ ring. The allyl and butadiene ligands are unfortunately disordered around a crystallographic mirror plane, so that the allyl carbon atoms are almost overlapping with three of the butadiene carbon atoms $[\mathrm{C}(7), \mathrm{C}(8)$ and $\mathrm{C}(9)]$. Although all carbon atoms were refined independently, the choice of which atom belongs to which ligand was somewhat arbitrary (see Experimental section), leading to uncertainties in the $\mathrm{C}-\mathrm{C}$ distances. Assuming the correctness of the choice made, the butadiene lateral C-C bonds are significantly shorter than the central $\mathrm{C}-\mathrm{C}$ bond, as would be expected for a diene ligand with little back-bonding. The same situation was found for the $\mathrm{Cp}_{2} \mathrm{Zr}($ s-trans-diene) derivatives (diene $=1,3$-butadiene, (E,E)-1,4-diphenyl-1,3-butadiene), 36,37 whereas the three bonds have similar lengths in $\mathrm{CpMo}(\mathrm{NO})(s$-trans-diene $) \quad($ diene $=$ (E)-1,3-pentadiene, 2,5-dimethyl-2,4-hexadiene $)$ derivatives. ${ }^{38,39}$ Future efforts will be directed at the synthesis and crystallographic characterization of derivatives with substituents on the diene and allyl ligands, with the hope of obtaining ordered crystal packings. 


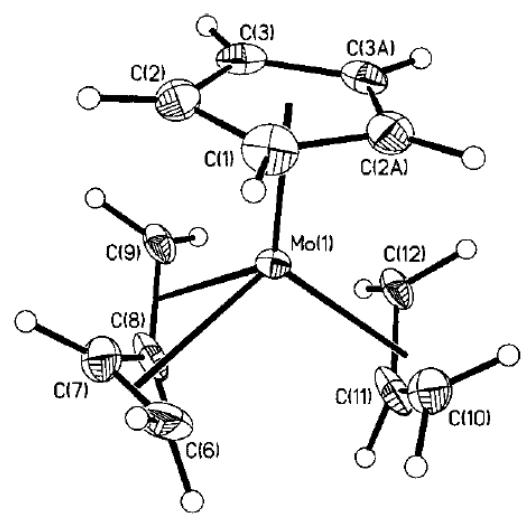

Figure 8. Molecular geometry of compound $\mathbf{4 c}$ with the numbering scheme employed. Only one of the two possible symmetry-related orientations of the diene and allyl ligands is shown for clarity. The ellipsoids are drawn at the $30 \%$ probability level.

\section{Discussion}

The $\left[\mathrm{CpMo}(\mu-X)\left(\eta^{4} \text {-butadiene }\right)\right]_{2}$ system. This work reports a new entry into $\mathrm{CpMo(II)}$ and $\mathrm{Mo}(\mathrm{III})$ complexes containing allyl and butadiene ligands. The Mo(II) complexes are obtained via the reduction of the $\mathrm{Mo}(\mathrm{III})$ precursor $\mathrm{CpMoCl}_{2}\left(\eta-\mathrm{C}_{4} \mathrm{H}_{6}\right)$, which is easily accessible via diene addition to $\mathrm{CpMoCl}_{2}$. The interaction of this material with allyl Grignard proceeds in two steps, the first one being one-electron reduction to compounds $\mathbf{2}$ and 3, and the second being halide substitution with an allyl ligand. The reduction step is accompanied by an unexpected halide exchange process between the two Lewis acids, Mo(II) and $\mathrm{Mg}(\mathrm{II})$, which may be related to the different affinities toward the Lewis bases $\mathrm{Cl}^{-}$and $\mathrm{Br}^{-}$ according to concept of hard and soft acids and bases [e.g. the softer Mo(II) prefers the softer $\mathrm{Br}^{-}$and the harder $\mathrm{Mg}(\mathrm{II})$ prefers the harder $\left.\mathrm{Cl}^{-}\right]$. The nature and relative amount of the products ( 2 and 3 in a 86:14 ratio) may be formally related to the equilibrium exchange process on the 16-electron "CpMoX $\left(\eta-\mathrm{C}_{4} \mathrm{H}_{6}\right)$ " (see Scheme 1) followed by combination of two 16electron $\mathrm{CpMoX}\left(\mathrm{C}_{4} \mathrm{H}_{6}\right)$ fragments. Theoretically, a dichloro-bridged compound should also be present, but its concentration was not sufficiently high for NMR detection. Under halideindependent enthalpic and entropic conditions for the dimerization process, a 0.927:0.073 ratio 
of species "CpMoBr$\left(\mathrm{C}_{4} \mathrm{H}_{6}\right)$ " and "CpMoCl$\left(\mathrm{C}_{4} \mathrm{H}_{6}\right)$ " would lead to $85.9 \%$ of $\mathbf{2}, 13.6 \%$ of $\mathbf{3}$, and only $0.5 \%$ of the unobserved compound $\left[\mathrm{CpMo}\left(\mathrm{C}_{4} \mathrm{H}_{6}\right)(\mu-\mathrm{Cl})\right]_{2}$.

\section{Scheme 1}

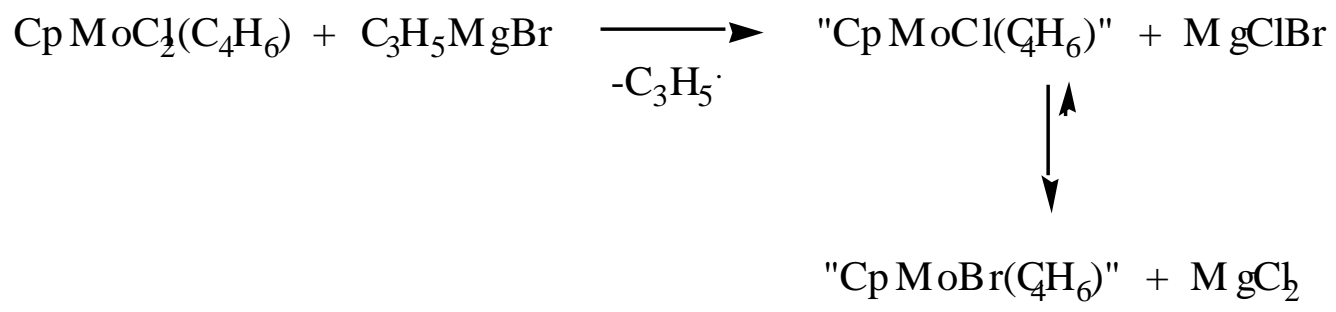

The relatively rapid syn/anti isomerization is likely to proceed via formation of 16electron mononuclear intermediates, $\mathrm{CpMoX}\left(\eta^{4}-\mathrm{C}_{4} \mathrm{H}_{6}\right)(\mathrm{X}=\mathrm{Cl}, \mathrm{Br})$. We have recently demonstrated that 16-electron phosphine-substituted half-sandwich Mo(II) derivatives, e.g. $\mathrm{CpMoCl}\left(\mathrm{PMe}{ }_{2} \mathrm{Ph}\right)_{2}, \mathrm{Cp} * \mathrm{MoCl}\left(\mathrm{PMe}_{3}\right)_{2}$ and $\mathrm{Cp} * \mathrm{MoCl}(\mathrm{dppe})$, can be generated and spectroscopically observed, and some are sufficiently stable to be isolated. ${ }^{40}$ The 16 -electron diene-containing intermediates, however, do not accumulate at sufficiently high levels for direct observation, and their formation is not sufficiently fast to coalesce the individual resonances of compounds $\mathbf{2 a}, \mathbf{2} \mathbf{b}, \mathbf{3 a}$, and $\mathbf{3 b}$. Only a slight broadening is observed upon heating a solution of $\mathbf{2} / \mathbf{3}$ in $\mathrm{C}_{6} \mathrm{D}_{6}$ to $120^{\circ} \mathrm{C}$ in a sealed NMR tube.

The 1:1 ratio of syn and anti isomers in solution for both dinuclear compounds $\mathbf{2}$ and 3 indicates little or no steric interaction between the ligands bonded to the two different metals. The previously reported isoelectronic complexes $\left[\left(\eta^{6}-\mathrm{C}_{6} \mathrm{H}_{6}\right) \mathrm{Mo}\left(\eta^{3}-\text { allyl }\right)(\mu-\mathrm{Cl})\right]_{2}$ could not be investigated by NMR because of low solubility, thus their relative syn/anti proportion is not known, ${ }^{41}$ although an X-ray structure of anti-[( $\left.\left.\eta^{6}-\mathrm{C}_{6} \mathrm{H}_{6}\right) \mathrm{Mo}\left(\eta^{3}-\mathrm{C}_{3} \mathrm{H}_{5}\right)(\mu-\mathrm{Cl})\right]_{2}$ has been determined. ${ }^{42}$ For the related compound $\left[\left(\eta^{6}-2,6-1 u t i d i n e\right) \operatorname{Mo}\left(\eta^{3}-\mathrm{C}_{3} \mathrm{H}_{5}\right)(\mu-\mathrm{Cl})\right]_{2}$ on the other hand, only one isomer has been reported in solution and the X-ray analysis shows the anti arrangement in the solid state. ${ }^{43}$ This phenomenon may be attributed to the large steric bulk of the 2,6-lutidine ligand. 
The $\operatorname{CpMo}\left(\eta^{3}\right.$-allyl $)\left(\eta^{4}\right.$-butadiene) system. Compound 4 is the first example of a CpMo(II) allyl-diene complex where the two open $\pi$-ligands are not linked with each other in a macrocyclic ligand, and it is the simplest possible example of this class. In previously reported cyclopentadienyl-allyl-diene-molybdenum(II) complexes, the rigid nature of the organic ligand does not allow any conformational flexibility. Examples are compounds V, where the allyl and diene moieties are forced to adopt the prone and supine conformations, ${ }^{44}$ and VI, where both moieties are forced in the prone conformation. ${ }^{45}$

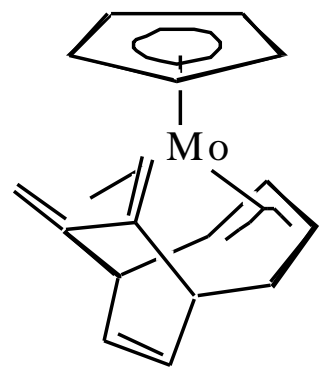

$\mathbf{V}$

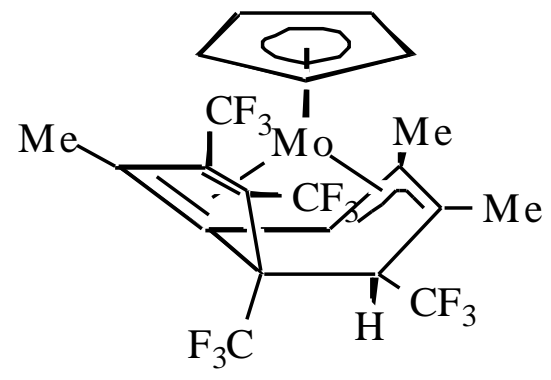

VI

Compound 4 has been observed in three different isomeric forms, which differ in the relative orientation of the allyl and diene ligands: the prone-allyl-supine-diene (4a), the supineallyl-supine-diene (4b), and the supine-allyl-s-trans-diene (4c). It is interesting to note that compound 4 is isolobally related to the previously reported $\left[\left(\eta^{6}\right.\right.$-arene $) \mathrm{Mo}\left(\eta^{3}-\mathrm{C}_{3} \mathrm{H}_{5}\right)\left(\eta^{4}-\right.$ $\left.\left.\mathrm{C}_{4} \mathrm{H}_{6}\right)\right]^{+}$, for which, however, different isomeric forms have apparently not been observed. ${ }^{41}$ Isomers $\mathbf{4 a}$ and $\mathbf{4 b}$ thermally interconvert at room temperature $\left(\mathrm{t}_{1 / 2}=6.5 \mathrm{~h}\right)$, leading to a 98:2 equilibrium mixture. The major conformation, thus, corresponds to that of the previously reported compound $\mathbf{V}$, whereas the rigid conformation of $\mathbf{V I}$ is not observed for compound 4. Isomer $\mathbf{4} \mathbf{c}$ is not accessible from $\mathbf{4 a}$ or $\mathbf{4 b}$ at room temperature, but can be obtained either thermally or photochemically, leading to a 1:1 equilibrium mixture of $\mathbf{4 a}$ and $\mathbf{4 c}$.

The most typical coordination mode of the butadiene ligand is s-cis. The s-trans coordination mode has been documented in few examples. ${ }^{4,26,46-48}$ The factors favoring one diene coordination mode versus the other are not well understood. For instance, the $s$-cis-diene complex was shown to be the kinetic product and to convert irreversibly to the more stable $s$ - 
trans-diene derivatives for the previously reported $\mathrm{CpMo}(\mathrm{NO})\left(\right.$ diene) systems. ${ }^{49,50}$ On the other hand, the behavior is exactly opposite for the zirconocene $\mathrm{Cp}_{2} \mathrm{Zr}$ (diene) derivatives, ${ }^{51}$ the cationic $\mathrm{Ru}(\mathrm{II})$ derivatives $[\mathrm{CpRu}(\mathrm{CO})(\text { diene })]^{+}, 46$ and for the cationic Mo(II) carbonyl complexes $\left[\mathrm{Cp} * \mathrm{Mo}(\mathrm{CO})_{2}(\text { diene })\right]^{+}, 47$ the kinetically controlled product being the $s$-trans and the thermodynamically more stable one being the $s$-cis.

The $\left[\mathrm{CpMo}\left(\eta^{3} \text {-allyl }\right)\left(\eta^{4} \text {-butadiene }\right)\right]^{+}$system. The only previously known organometallic $\mathrm{Mo}(\mathrm{III})$ compounds containing only Mo-C bonds are $\mathrm{CpMo}\left(\eta^{3} \text {-allyl }\right)_{2}$ and analogues with substituted $\mathrm{Cp}$ rings, 34,35 and the one-electron oxidization product of system V. 44 The potentials for the oxidation of $\mathbf{4}$ to $\mathbf{5}$ are in the range observed for $\mathrm{Cp}^{*} \mathrm{MoCl}(\mathrm{CO}) \mathrm{L}_{2}$ derivatives (e.g. $\mathrm{E}_{1 / 2}=-0.48 \mathrm{~V}$ for $\mathrm{L}=\mathrm{PMe}_{3}$ and $-0.44 \mathrm{~V}$ for $\mathrm{L}_{2}=$ dppe), ${ }^{52}$ whereas compound 1 is more stable in the Mo(III) neutral form relative to the reduced $\mathrm{Mo}(\mathrm{II})$ anion $\left(\mathrm{E}_{1 / 2}=-1.03\right.$ V). ${ }^{14}$ Dihalobis(phosphine) derivatives of Mo(III) are electronically even richer and cannot be reduced to the 18-electron Mo(II) anions (they are rather oxidized to the paramagnetic 16electron Mo(IV) cations). ${ }^{53}$

The oxidized compound $\mathbf{5}$ has been observed in four isomeric forms, three of which correspond to those of the neutral precursor, $\mathbf{5 a}, \mathbf{5 b}, \mathbf{5 c}$, and $\mathbf{5 d}$. In this case, the isomeric preference is different, isomer 5a transforming rapidly $\left(\mathrm{t}_{1 / 2}<20 \mathrm{~s}\right)$ to isomer $\mathbf{5 b}$. Compound $\mathbf{V}$ has also been reported ${ }^{44}$ to undergo a one-electron oxidation to the corresponding cation. However, the nature of the macrocyclic ligand locks $[\mathbf{V}]^{+}$(a green compound like 5a) in the same prone-allyl-supine-diene conformation observed for $\mathbf{V}$. Isomer $\mathbf{5 c}$, obtained by 1electron oxidation of $\mathbf{4 c}$, is in fast equilibrium with $\mathbf{5 d}$, but both of these slowly convert to the most stable isomer $\mathbf{5 b}$. Because of solubility problems in THF and stability problems in $\mathrm{CH}_{2} \mathrm{Cl}_{2}$, rate information could not be gathered on this conversion process. The overall transformations are summarized in Scheme 2.

\section{Scheme 2}




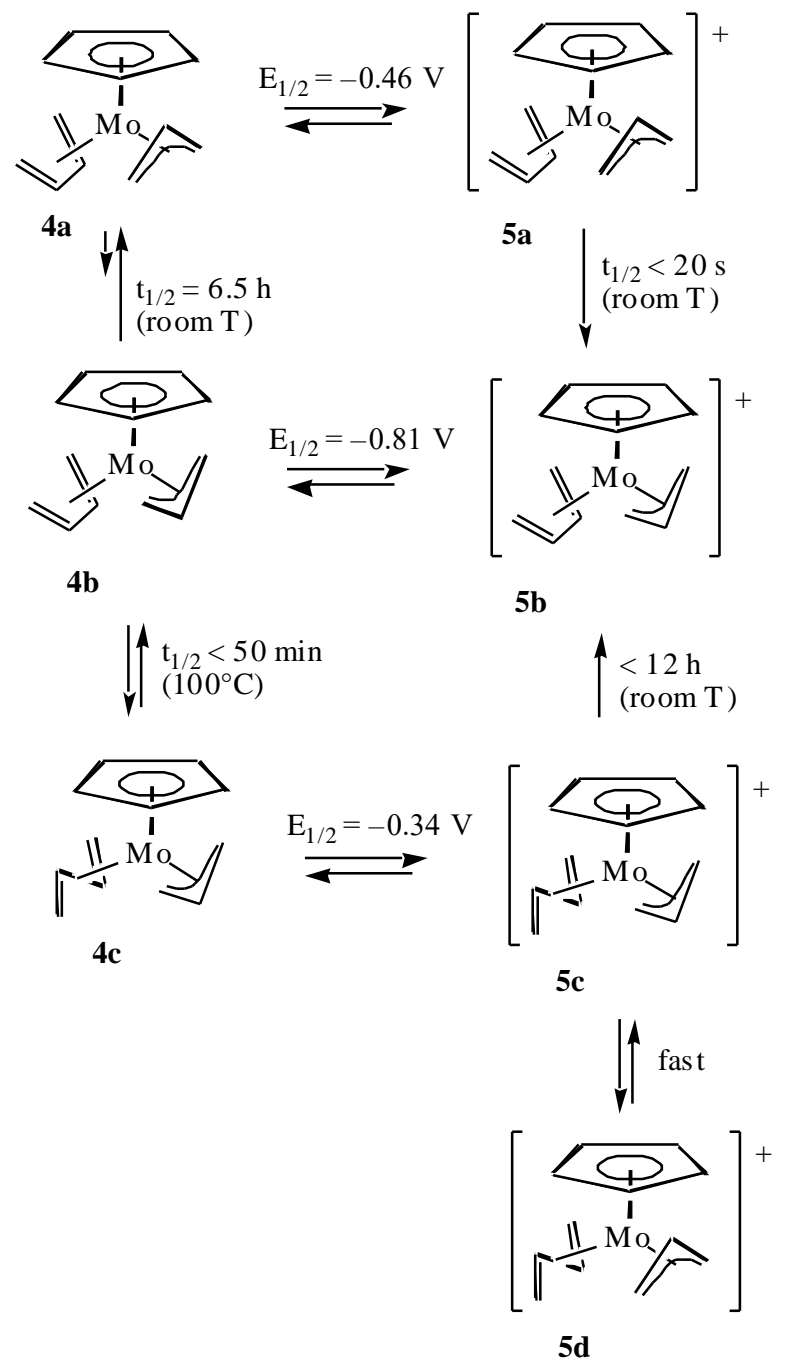

Thermodynamics and kinetics. From the equilibrium distributions, rate data, and electrochemical data an almost complete energetic picture can be derived. Compounds $\mathbf{4 a}$ and 4c (1:1 at equilibrium) have approximately the same free energy, whereas $\mathbf{4 b}$ is $2.3 \mathrm{kcal} / \mathrm{mol}$ higher. The half-life of $6.5 \mathrm{~h}$ for the transformation of $\mathbf{4 b}$ to the $\mathbf{4 a} / \mathbf{4 b}$ equilibrium yields $\left(\mathrm{k}_{1}+\mathrm{k}_{-1}\right) \approx 3.0 \cdot 10^{-5} \mathrm{~s}^{-1}$ which, with the independent knowledge of the equilibrium constant $\left(\mathrm{k}_{1} / \mathrm{k}_{-1}=98: 2\right)$ yields $\mathrm{k}_{1} \approx 2.9 \cdot 10^{-5} \mathrm{~s}^{-1}$ and $\Delta \mathrm{G}_{1}+=23.6 \mathrm{kcal} / \mathrm{mol}$ at $298 \mathrm{~K}$. Analogously, from the rate of interconversion of $\mathbf{4 a}$ to the $1: 1$ equilibrium mixture of $4 \mathbf{c}$ and $\mathbf{4 a}$ at $100^{\circ} \mathrm{C}$ ( 3 halflives $<2.5 \mathrm{~h}$ ), the activation free energy for this process is calculated as $\Delta \mathrm{G} *<30.2 \mathrm{kcal} / \mathrm{mol}$. If we consider, as a first approximation, that reaction and activation entropies for these isomerization processes are small, these values can be directly taken as enthlapies and compared on the same temperature independent diagram (see Figure 9). 


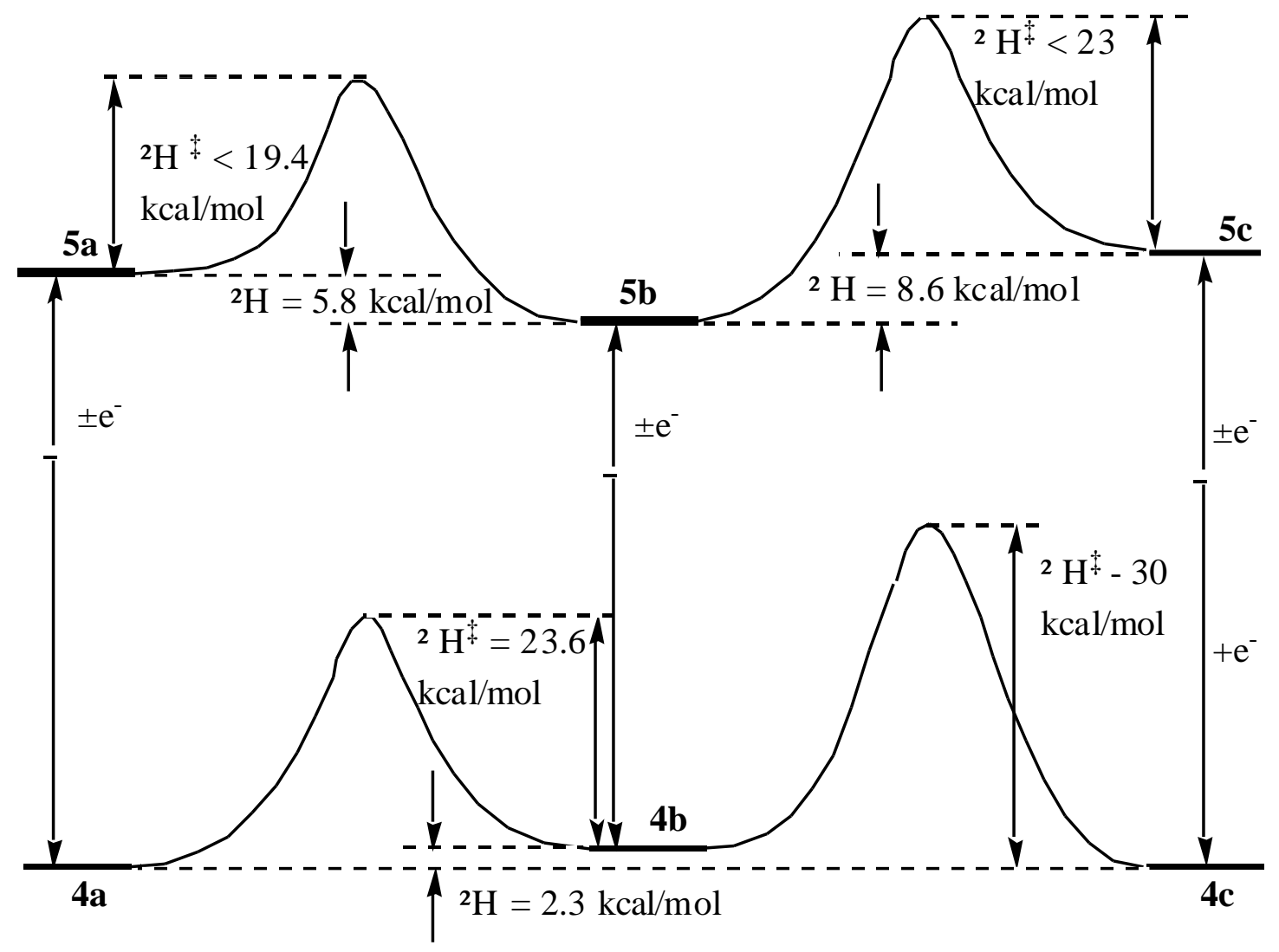

Figure 9. Thermodynamic and kinetic parameters related to the processes in Scheme 2.

The relative free energies (and thus, enthalpies under the same assumption of negligible entropic term) in the oxidized manifold can be related to the relative free energies of the neutral Mo precursors by the oxidation potentials of the three half-reactions. This calculation confirms that compounds $\mathbf{5 a}$ and $\mathbf{5 c}$ are thermodynamically unstable with respect to the complete isomerization to $\mathbf{5 b}$, as experimentally observed. The energy of $\mathbf{5 d}$ relative to $\mathbf{5 c}$ cannot be established with certainty, since these two complexes are observed in a rapid equilibrium only in solutions that are saturated in both. The activation parameters for the interconversion of $\mathbf{5 a}$ to $\mathbf{5 b}$ is derived as illustrated above for the isomerization in the Mo(II) manifold from the half life of the conversion $(<20 \mathrm{~s}$ at room temperature). No significant rate information could be obtained for the other transformations, although the quantitative conversion ( $>4$ half lives) of both $\mathbf{5 c}$ and $\mathbf{5 d}$ to $\mathbf{5 b}$ in less than $12 \mathrm{~h}\left(\mathrm{t}_{1 / 2}<3 \mathrm{~h}\right)$ establishes an upper limit of $23 \mathrm{kcal} / \mathrm{mol}$ for 
$\Delta \mathrm{G}+$ of this process. The real value, however, may be considerably lower since most of the reagents are in the solid state during the experiment.

Mechanistic considerations. The isomerization of either $4 \mathbf{b}$ to $\mathbf{4 a}, \mathbf{5 a}$ to $\mathbf{5 b}$, or $\mathbf{5 d}$ to 5c involves a formal $180^{\circ}$ rotation of the allyl ligand around the Mo-allyl axis. The actual mechanism of these isomerization processes, however, does not necessarily involve the rotation of the ligand. An alternative is the rearrangement of the allyl ligand from $\eta^{3}$ to $\eta^{1}$, followed by rotation around the $\mathrm{Mo}-\mathrm{CH}_{2}$ or the $\mathrm{CH}_{2}-\mathrm{CH}$ bond and recoordination. The high barriers to these processes are consistent with significant loss of bonding in either case. It is interesting to observe that the barriers are significantly smaller for the 17-electron Mo(III) complexes. It is well established that nondissociative isomerization processes in 18-electron organometallics are significantly accelerated by one-electron oxidation. ${ }^{54}$ A dissociative isomerization (i.e. via a $\eta^{3}$ to $\eta^{1}$ allyl rearrangement) would seem inconsistent in principle with the relative rates, because the allyl ligand might reasonably be expected to bind more strongly to the higher oxidation state metal center. In addition, preliminary results of ligand additions processes, which will be reported in a future contribution, show substitution of the butadiene ligand rather than addition with rearrangement of the allyl ligand. The latter argument, however, only proves a thermodynamic preference for the diene substitution reaction and does not necessarily disprove an allyl rearrangement mechanism for the isomerization process.

Compounds 4/5c differ from 4/5b (and correspondingly 5d from 5a) only in the stereochemistry of the diene ligand (s-trans in the former, supine-s-cis in the latter). It is therefore likely that the isomerization of $\mathbf{4 / 5} \mathbf{a}$ to $\mathbf{4 / 5} \mathbf{c}$ and viceversa occurs via compounds $4 / \mathbf{5 b}$ and, likewise, that the isomerization of $\mathbf{5 d}$ to $\mathbf{5 b}$ occurs via compound $\mathbf{5 c}$. The cis-trans isomerization of the coordinated diene must necessarily involve dissociation of at least one of the two ene functions and rotation around the diene C-C single bond (see Scheme 3). The barrier to this interconversion is the highest amongst those shown in Figure 9, which would seem to support the idea that the above discussed interconversion of prone and supine allyl involves a nondissociative rotation. 


\section{Scheme 3}

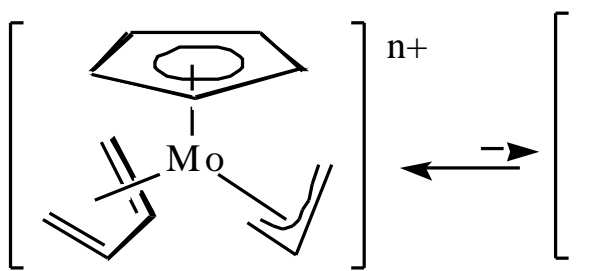

$4 / 5 b$

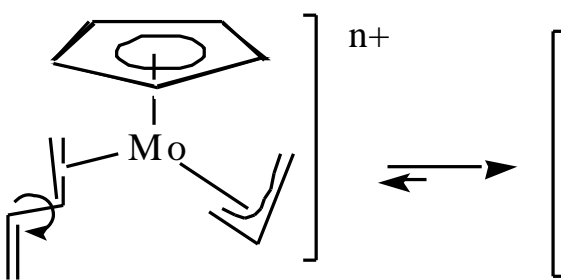

$\mathrm{n}=0,16-\mathrm{e}$

$\mathrm{n}=1,15-\mathrm{e}$

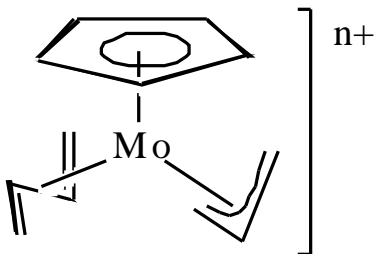

$4 / 5 c$

There are a few previously published observations of rates of interconversion of $s$-cis and s-trans diene ligands, but the factors affecting these rates do not seem obvious. For instance, at one extreme we find the niobium complexes $\mathrm{CpNb}$ (supine-s-cis- $\left.\mathrm{C}_{4} \mathrm{H}_{6}\right)($ prone-scis- $\left.\mathrm{C}_{4} \mathrm{H}_{6}\right)$ and $\mathrm{CpNb}\left(s-\right.$ cis- $\left.\mathrm{C}_{4} \mathrm{H}_{6}\right)\left(\right.$ s-trans $\left.-\mathrm{C}_{4} \mathrm{H}_{6}\right)$ which do not interconvert at $80^{\circ} \mathrm{C}$, while at the other we have a variety of $\left[\mathrm{Cp}^{*} \mathrm{Mo}(\mathrm{CO})_{2}(\right.$ exo( or endo $)$-s-trans-(E)-1-R $1-3-\mathrm{R}^{2}-4-\mathrm{X}-1,3-$ butadiene $)]^{+}\left(\mathrm{X}=\mathrm{OH}\right.$ or $\mathrm{CH}_{3}, \mathrm{R}^{1}, \mathrm{R}^{2}=\mathrm{H}$ or $\left.\mathrm{CH}_{3}\right)$ which can only be generated under kinetically controlled conditions at low temperatures, but rearrange rapidly to the more stable exo(or endo)-s-cis analogues. ${ }^{47}$ Our molecules have an intermediate behavior, being inert but isomerizing upon warming to $100^{\circ} \mathrm{C}$. The difference in rates between the two isoelectronic dicarbonyl and allyl Mo(II) systems is particularly striking. This difference indicates that the Mo-ene bond is stronger in compound 4 than in the cationic dicarbonyl analogues. Since the $\mathrm{Cp} * \mathrm{Mo}(\mathrm{CO})_{2}{ }^{+}$unit is reasonably expected to be more electron deficient than the CpMo(allyl) unit, the obvious conclusion seems that the major contribution to the Mo-ene bond stabilization comes from the $\pi$ back-bonding component. Particularly striking is also the faster conversion of $\mathbf{5 c}$ to $\mathbf{5 b}$ relative to that of $\mathbf{4 b}$ to $\mathbf{4 c}$. This finding may be rationalized in the same fashion: the weaker Mo-ene bond for Mo(III) than for Mo(II) may be related to the expected weakening of the $\pi$ back-bonding component, implying a greater importance of the $\pi$ relative to the $\sigma$ component for the Mo-ene bond stabilization.

There is, however, a second and more subtle way to rationalize a faster $s$-cis/s-trans isomerization for 5 relative to 4 . A factor that may provide greater stabilization of the unsaturated intermediate for the higher oxidation state system is the regain of pairing energy 55 
if the 15-electron $\mathrm{Mo}(\mathrm{III})$ complex is more stable in a $\mathrm{S}=3 / 2$ state. Calculations at both the MP2 and DFT level have shown 56 that the related 15-electron $\mathrm{CpMoCl}_{2}\left(\mathrm{PH}_{3}\right)$ compound (a model of the proven dissociative intermediate of the phosphine exchange on $\left.\mathrm{CpMoCl}_{2} \mathrm{~L}_{2}\right)^{57}$ has a spin quartet ground state, stabilized by several $\mathrm{kcal} / \mathrm{mol}$ over the alternative doublet state. Differences in pairing energy stabilization could also, in principle, rationalize the faster isomerization for the $\left[\mathrm{Cp} * \mathrm{Mo}(\mathrm{CO})_{2}\left(\eta^{4} \text {-diene }\right)\right]^{+}$system, in case the 16-electron $\left[\mathrm{Cp} * \mathrm{Mo}(\mathrm{CO})_{2}\left(\eta^{2} \text {-diene }\right)\right]^{+}$intermediate adopts a spin triplet state, because the expected higher effective positive charge for the cationic dicarbonyl derivative relative to the neutral allyl derivative should give rise to greater pairing energies and, consequently, greater stabilization of an unsaturated spin triplet state. Examples of stable 16-electron organometallic Mo(II) complexes with a spin triplet ground state have been found recently, i.e. $\mathrm{Cp}^{*} \mathrm{MoClL}_{2}(\mathrm{~L}=$ $\mathrm{PMe}_{3}, \mathrm{PMe}_{2} \mathrm{Ph}$ or $\left.\mathrm{L}_{2}=\mathrm{dppe}\right)^{40,58}$ and $\left[\mathrm{HB}\left(3,5-\mathrm{Me}_{2} \mathrm{Pz}\right)_{3}\right] \mathrm{MoI}(\mathrm{CO})_{2} .59$

\section{Conclusions}

The synthesis of the allyl-butadiene complex $\mathrm{CpMo}\left(\eta^{3}-\mathrm{C}_{3} \mathrm{H}_{5}\right)\left(\eta^{4}-\mathrm{C}_{4} \mathrm{H}_{6}\right)$ and its 1electron oxidation product has revealed a complex stereochemical behavior, with relative energies and rates of isomer interconversion that depend on the metal oxidation state. The preference for the relative orientation of the allyl and butadiene in the coordination sphere of the same metal may be relevant for the stereocontrol of diene polymerization processes. It has been established that, for active nickel catalysts, the control of the mode of diene coordination is crucial for the stereocontrol of the polybutadiene product, with the $\left[\mathrm{Ni}\left(\eta^{3}-\right.\right.$ allyl $)\left(\eta^{4}-S-c i s-\right.$ diene $)]^{+}$intermediates leading to a 1,4-cis polymer and the $\left[\mathrm{NiL}\left(\eta^{3} \text {-allyl }\right)\left(\eta^{2} \text {-s-trans-diene }\right)\right]^{+}$ intermediates leading to a 1,4-trans polymer. ${ }^{11}$ Since preliminary observations indicate catalytic activity of $\mathbf{4}$ for butadiene polymerization, a thorough study of this catalytic process might add useful knowledge to the details of the stereocontrol mechanism. It will also be interesting to investigate the cationic Mo(III) systems 5 as polymerization catalysts, in view of the demonstrated greater lability of the Mo-ene bonds for this system. 
Acknowledgment. We are grateful to the National Science Foundation (CHE9508521) for support of this work. The EPR upgrade was made possible in part by a NSF shared equipment grant (CHE-9225064).

Supporting Information Available. For the X-ray structures of compounds 2/3, 4a, $\mathbf{5 b}$, and 4c: detailed description of experimental procedures, tables of crystal data and refinement parameters, fractional atomic coordinates, full tables of bond distances and angles, anisotropic thermal parameters, and hydrogen atom coordinates (40 pages). Supplemental Figures of 2D-COSY and ${ }^{1} \mathrm{H}-{ }^{13} \mathrm{C}-\mathrm{HMQC}-\mathrm{NMR}$ spectra for compounds $\mathbf{4 a}$ and $\mathbf{4 c}$ (4 pages). This material is contained in many libraries on microfiche, immediately follows this article in the microfilm version of the journal, can be ordered from the ACS, and can be downloaded from the Internet; see any current masthead page for ordering information and Internet access instructions. 


\section{References}

(1) (a) University of Maryland. (b) Université de Bourgogne.

(2) Jolly, P. W.; Wilke, G. The Organic Chemistry of Nickel; Academic Press: New York, 1974; Vol. 1.

(3) Birch, A. J.; Jenkins, I. D. In Transition Metal Organometallics in Organic synthesis; H. Alper, Ed.; Academic Press: New York, 1976; Vol. 1; pp 1-82.

(4) Erker, G.; Kruger, C.; Muller, G. Adv. Organomet. Chem. 1985, 24, 1-39, and references therein.

(5) Yasuda, H.; Nakamura, A. Angew. Chem. Int. Ed. Engl. 1987, 26, 723-742.

(6) Boor, J., Jr. Ziegler-Natta Catalysts and Polymerization; Academic Press: New York, 1979, pp 130-154, 422-441.

(7) Gabassi, F.; Italia, S.; Ricci, G. In Transition Metal Catalyzed Polymerizations; R. P. Quirk, Ed.; Cambridge University Press: Cambridge, 1988; pp 655-670.

(8) Teyssié, P.; Hadjiandreou, P.; Julémont, M.; Warin, R. In Transition Metal Catalyzed Polymerizations; R. P. Quirk, Ed.; Cambridge University Press: Cambridge, 1988; pp 639-654.

(9) Porri, L.; Giarrusso, A. In Comprehensive Polymer Science; G. C. Eastmond, A. Ledwith, S. Russo and P. Sigwalt, Ed.; Pergamon Press: Oxford, 1989; Vol. 4, Part II; pp 53-108.

(10) Porri, L.; Giarrusso, A.; Ricci, G. Prog. Polym. Sci. 1991, 16, 405-441.

(11) Tobisch, S.; Bögel, H.; Taube, R. Organometallics 1996, 15, 3563-3571, and references therein.

(12) Abugideiri, F.; Kelland, M. A.; Poli, R. Organometallics 1992, 11, 1311-1318.

(13) Linck, R. G.; Owens, B. E.; Poli, R.; Rheingold, A. L. Gazz. Chim. Ital. 1991, 121, 163-168.

(14) Davidson, J. L.; Davidson, K.; Lindsell, W. E.; Murrall, N. W.; Welch, A. J. J. Chem. Soc., Dalton Trans, 1986, 1677-1688. 
(15) Davidson, J. L.; Davidson, K.; Lindsell, W. E. J. Chem. Soc., Chem. Commun. 1983, $452-453$.

(16) Bax, A. J. Magn. Res. 1983, 53, 517-520.

(17) Bax, A.; Subramanian, S. J. Magn. Res. 1986, 67, 565-569.

(18) Mann, B. E.; Taylor, B. F. 13-C NMR data for organometallic compounds; Academic Press: London, 1981, pp 200, 211.

(19) Friebolin, H. Basic One- and Two-Dimensional NMR Spectrocopy; VCH: Weinheim, 1991, pp 95.

(20) Faller, J. W.; Chen, C.-C.; Mattina, M. J.; Jakubowski, A. J. Organomet. Chem. 1973, $52,361-386$.

(21) Faller, J. W.; Johnson, B. V.; Dryja, T. P. J. Organomet. Chem. 1974, 65, 395-400.

(22) Gibson, D. H.; Hsu, W.-L.; Steinmetz, A. L.; Johnson, B. V. J. Organomet. Chem. 1981, 208, 89-102.

(23) Erker, G.; Berg, K.; Krüger, C.; Müller, G.; Angermund, K.; Benn, R.; Schroth, G. Angew. Chem., Int. Ed. Engl. 1984, 23, 455.

(24) Doddrell, D. M.; Pegg, D. T.; Bendall, M. R. J. Magn. Res. 1982, 48, 323.

(25) Yamamoto, A. Organotransition Metal Chemistry-Fundamental Concepts and Applications; John Wiley and Sons: New York, 1986.

(26) Okamoto, T.; Yasuda, H.; Nakamura, A.; Kai, Y.; Kanehisa, N.; Kasai, N. J. Am. Chem. Soc. 1988, 110, 5008-5017.

(27) Blenkers, J.; Hessen, B.; van Bolhuis, F.; Wagner, A. J.; Teuben, J. H. Organometallics 1987, 6, 459-469.

(28) Yasuda, H.; Tatsumi, K.; Okamoto, T.; Mashima, K.; Lee, K.; Nakamura, A.; Kai, Y.; Kanehisa, N.; Kasai, N. J. Am. Chem. Soc. 1985, 107, 2410-2422.

(29) Mashima, K.; Tanaka, Y.; Kaidzu, M.; Nakamura, A. Organometallics 1996, 15, 24312433.

(30) Beevor, R. G.; Freeman, M. J.; Green, M.; Morton, C. E.; Orpen, A. G. J. Chem. Soc., Dalton Trans. 1991, 3021-3030. 
(31) Greenhough, T. J.; Legzdins, P.; Martin, D. T.; Trotter, J. Inorg. Chem. 1979, 18, 32683270 .

(32) Faller, J. W.; Chodosh, D. F.; Katahira, D. J. Organomet. Chem. 1980, 187, 227-231.

(33) Poli, R.; Mattamana, S. P.; Falvello, L. R. Gazz. Chim. Ital. 1992, 122, 315-319.

(34) Jolly, P. W.; Krüger, C.; Romão, C. C.; Romão, M. J. Organometallics 1984, 3, 936937.

(35) Andell, O.; Goddard, R.; Holle, S.; Jolly, P. W.; Krüger, C.; Tsay, Y. H. Polyhedron 1989, $8,203-209$.

(36) Erker, G.; Wicher, J.; Engel, K.; Kruger, C. Chem. Ber. 1982, 115, 3300-3310.

(37) Kai, Y.; Kanehisa, N.; Miki, K.; Kasai, N.; Mashima, K.; Nagasuna, K.; Yasuda, H.; Nakamura, A. J. Chem. Soc., Chem. Comm. 1982, 191-192.

(38) Hunter, A. D.; Legzdins, P.; Nurse, C. R.; Einstein, F. W. B.; Willis, A. C. J. Am. Chem. Soc. 1985, 107, 1791-1792.

(39) Christensen, N. J.; Legzdins, P.; Einstein, F. W. B.; Jones, R. H. Organometallics 1991, $10,3070-3080$.

(40) Abugideiri, F.; Fettinger, J. C.; Keogh, D. W.; Poli, R. Organometallics 1996, 15, 4407-4416.

(41) Green, M. L. H.; Knight, J. J. Chem. Soc., Dalton Trans. 1974, 311-319.

(42) Prout, K.; Rees, G. V. Acta Cryst. 1974, B30, 2251-2252.

(43) Mehnert, C. P.; Chernega, A. N.; Green, M. L. H. J. Organomet. Chem. 1996, 513, 247-253.

(44) Brammer, L.; Dunne, B. J.; Green, M.; Moran, G.; Orpen, A. G.; Reeve, C.;

Schaverien, C. J. J. Chem. Soc., Dalton Trans. 1993, 1747-1759.

(45) Carfagna, C.; Green, M.; Mahon, M. F.; McInnes, J. M.; Rumble, S. J.; Woolhouse, C. M. J. Chem. Soc., Dalton Trans. 1996, 3379-3385.

(46) Benyunes, S. A.; Day, J. P.; Green, M.; Al-Saadoon, A. W.; Waring, T. L. Amgew. Chem., Int. Ed. Engl. 1990, 29, 1416-1417.

(47) Benyunes, S. A.; Binelli, A.; Green, M.; Grimshire, M. J. J. Chem. Soc., Dalton Trans. 1991, 895-904. 
(48) Christensen, N. J.; Legzdins, P.; Trotter, J.; Yee, V. C. Organometallics 1991, 10, 4021-4030.

(49) Hunter, A. D.; Legzdins, P.; Einstein, F. W. B.; Willis, A. C.; Bursten, B. E.; Gatter, M. G. J. Am. Chem. Soc. 1986, 108, 3843-3844.

(50) Christensen, N. J.; Hunter, A. D.; Legzdins, P. Organometallics 1989, 8, 930-940.

(51) Erker, G.; Wicher, J.; Engel, K.; Rosenfeldt, F.; Dietrich, W.; Krüger, C. J. Am. Chem. Soc. 1980, 102, 6344-6346.

(52) Fettinger, J. C.; Keogh, D. W.; Poli, R. J. Am. Chem. Soc. 1996, 118, 3617-3625.

(53) Poli, R. J. Coord. Chem. B 1993, 29, 121-173.

(54) Trogler, W. C. In Organometallic radical processes; W. C. Trogler, Ed.; Elsevier: Amsterdam, 1990; Vol. 22; pp 306-337, and references therein.

(55) Poli, R. Chem. Rev. 1996, 96, 2135-2204.

(56) Cacelli, I.; Keogh, D. W.; Poli, R.; Rizzo, A. New J. Chem. 1997, 21, 133-135.

(57) Cole, A. A.; Fettinger, J. C.; Keogh, D. W.; Poli, R. Inorg. Chim. Acta 1995, 240, $355-$ 366.

(58) Abugideiri, F.; Keogh, D. W.; Poli, R. J. Chem. Soc., Chem. Commun. 1994, $2317-$ 2318 .

(59) Saleh, A. A.; Pleune, B.; Fettinger, J. C.; Poli, R. Polyhedron 1977, 16, 1391-1397. 